\title{
OB-fold domain of KREPA4 mediates high-affinity interaction with guide RNA and possesses annealing activity
}

\author{
SMRITI KALA ${ }^{1}$ and REZA SALAVATI ${ }^{1,2,3}$ \\ ${ }^{1}$ Institute of Parasitology, McGill University, Ste. Anne de Bellevue, Quebec H9X 3V9, Canada \\ ${ }^{2}$ McGill Centre for Bioinformatics, McGill University, Montreal, Quebec H3A 2B4, Canada \\ ${ }^{3}$ Department of Biochemistry, McGill University, Montreal, Quebec H3G 1Y6, Canada
}

\begin{abstract}
KREPA4, also called MP24, is an essential mitochondrial guide RNA (gRNA)-binding protein with a preference for the 3' oligo(U) tail in trypanosomes. Structural prediction and compositional analysis of KREPA4 have identified a conserved OB (oligonucleotide/oligosaccharide-binding)-fold at the C-terminal end and two low compositional complexity regions (LCRs) at its $\mathbf{N}$ terminus. Concurrent with these predictions, one or both of these regions in KREPA4 protein may be involved in gRNA binding. To test this possibility, deletion mutants of KREPA4 were made and the effects on the gRNA-binding affinities were measured by quantitative electrophoretic mobility shift assays. The gRNA-binding specificities of these mutants were evaluated by competition experiments using gRNAs with U-tail deletions or stem-loop modifications and uridylated nonguide RNAs or heterologous RNA. Our results identified the predicted OB-fold as the functional domain of KREPA4 that mediates a highaffinity interaction with the gRNA oligo(U) tail. An additional contribution toward RNA-binding function was localized to LCRs that further stabilize the binding through sequence-specific interactions with the guide secondary structure. In this study we also found that the predicted OB-fold has an RNA annealing activity, representing the first report of such activity for a core component of the RNA editing complex.
\end{abstract}

Keywords: RNA editing; RNA-binding; RNA annealing; KREPA4; OB-fold

\section{INTRODUCTION}

Most mitochondrial mRNAs in trypanosomatids require editing, which is the post-transcriptional insertion and deletion of uridylates (U's) that are specified by guide RNAs (gRNAs) and catalyzed by multiprotein complexes (for reviews, see Madison-Antenucci et al. 2002; Simpson et al. 2004; Lukes et al. 2005; Stuart et al. 2005). One complex that sediments at $\sim 20 \mathrm{~S}$ in glycerol gradients (20S editosome) contains the four key enzyme activities and can accurately edit single sites in vitro (Seiwert et al. 1996). In the first enzymatic step, an editing-site-specific endonuclease recognizes the mRNA/gRNA anchor duplex and cleaves the mRNA $3^{\prime}$ to the first unpaired nucleotide. Next, U's are either added to the $5^{\prime}$ cleavage fragment by a terminal

Reprint requests to: Reza Salavati, Institute of Parasitology, McGill University, 21111 Lakeshore Road, Ste. Anne de Bellevue, Quebec H9X 3V9, Canada; e-mail: reza.salavati@mcgill.ca; fax: (514) 398-7857.

Article published online ahead of print. Article and publication date are at http://www.rnajournal.org/cgi/doi/10.1261/rna.2124610. uridylyl transferase (TUTase) in insertion editing or removed by a $3^{\prime} \mathrm{U}$-specific exonuclease in deletion editing, as specified by the sequence of the gRNA. Finally, RNA ligase rejoins the two halves of the mRNA. Several cycles of coordinated catalytic steps occur until all of the sites specified by a gRNA are edited, resulting in complementarity between the edited mRNA and the gRNA.

Structure analysis of gRNAs has identified a conserved secondary structure at their most $5^{\prime}$ end, known as the anchor sequence, consisting of two stem-loop regions (Schmid et al. 1995; Hermann et al. 1997). Editing proceeds 3' to 5 ' with the initial gRNAs forming an "anchor" duplex using the anchor sequence with the pre-mRNA immediately $3^{\prime}$ to the first block of sequence to be edited. The central portion of the gRNA contains the editing information and all gRNAs have a $3^{\prime}$ oligo(U) tail of variable length that is added posttranscriptionally by a $3^{\prime}$ TUTase (Aphasizhev et al. 2002). The U-tail has been proposed to have a role in stabilizing the interaction between the gRNA and the 5 ' region of the premRNA (Koslowsky et al. 2004). 
The 20S editosome contains at least 20 proteins (kinetoplastid RNA editing proteins [KREPs]) that have predicted catalytic and/or RNA interaction motifs (Worthey et al. 2003; Stuart et al. 2005). Editosome proteins that lack catalytic motifs but have motifs suggestive of RNA and/or protein interaction include KREPA proteins. These proteins are characterized by oligonucleotide/oligosaccharide-binding (OB) fold motifs with a subset also possessing a pair of conserved $\mathrm{C} 2 \mathrm{H} 2$ zinc-finger ( $\mathrm{Zf}$ ) domains (Panigrahi et al. 2001; Schnaufer et al. 2003; Worthey et al. 2003). OB-fold and $\mathrm{Zf}$ domains function in nucleic acid recognition or protein binding (Matthews and Sunde 2002; Theobald et al. 2003). Interactions in the core of the $20 \mathrm{~S}$ editosome, which are essential for complex stability, all appear to be mediated via OB-fold-containing proteins, with the OBfolds from different KREPA proteins interacting with each other (Schnaufer et al. 2010). Down-regulation of expression of each of these proteins inhibits cell growth and results in partial or complete disruption of $20 \mathrm{~S}$ editosomes (Drozdz et al. 2002; Huang et al. 2002; O'Hearn et al. 2003; Brecht et al. 2005; Salavati et al. 2006; Guo et al. 2008). Thus, the OB-foldcontaining KREPA family members not only mediate RNA substrate binding but are also essential for the structural integrity of the $20 \mathrm{~S}$ editosome.

The editing process involves other complexes and accessory factors that are not directly a part of the 20 S editosome, but indirectly regulate the efficiency of editing and editosome stability. These include several mitochondrial RNA-binding proteins such as RBP16, MRP1/MRP2, REAP1, TbRGG1, and the recently discovered MRB1 complex (Koller et al. 1997; Madison-Antenucci et al. 1998; Vanhamme et al. 1998; Hayman and Read 1999; Blom et al. 2001; Hashimi et al. 2008; Panigrahi et al. 2008; Acestor et al. 2009). Among these proteins, the MRP1/MRP2 complex and RBP16 are two factors that exhibit similar nonspecific RNA-binding and RNA annealing activities (Muller et al. 2001; Ammerman et al. 2008; Fisk et al. 2009).

KREPA4, as it will be addressed here, was previously designated as TbMP24 and has recently been named MP24 (Simpson et al. 2010). It is an essential editosome protein belonging to the KREPA family. This protein is predicted to have a conserved OB-fold at its C-terminal region (Worthey et al. 2003). In addition, structural prediction and compositional analysis of KREPA4 have predicted a putative S1 motif within the OB-fold and two low compositional complexity regions (LCRs) (Salavati et al. 2006). The S1 motif is a type of OB-fold that is found in a large number of RNA-associated proteins (Bycroft et al. 1997). LCRs are protein portions exhibiting a biased amino acid composition, most often associated with protein-protein interactions (Wootton and Federhen 1996). With the LCRs, which are rich in arginine and glycine residues and a putative OB-fold/S1 motif, KREPA4 has been characterized as a gRNA-binding protein with preferential binding specificity toward the $3^{\prime}$ oligo(U) tail (Salavati et al. 2006). Here we map the RNA-binding domain of KREPA4 by analyzing the RNA-binding activities of the full-length and truncated versions of this protein. Our results lead to a model that demonstrates the potential RNAbinding surface of KREPA4 is mainly localized to the predicted OB-fold at the C-terminal region of the protein, which mediates a high-affinity binding interaction with the gRNA U-tail while the LCRs further stabilize the binding by sequence-specific interactions with the guide stem-loop elements. We also show that KREPA4 has RNA annealing activity, as it is able to stimulate gRNA/pre-mRNA hybrid formation. This activity seems to be correlated with the highaffinity OB-fold-mediated binding to the gRNA oligo(U) tail and is specific for RNA editing substrates. Cumulatively, these data suggest that the OB-fold of KREPA4 not only is involved in high-affinity substrate binding but also assists during the hybrid formation between gRNAs and cognate pre-mRNAs in the initial steps of the editing reaction.

\section{RESULTS}

\section{Expression and purification of KREPA4 deletion variants}

To map the gRNA-binding domain of KREPA4, based on sequence and structure analyses previously reported (Worthey et al. 2003; Salavati et al. 2006) and a new secondary structure analysis in this study, recombinant full-length and truncated versions of KREPA4 with an N-terminal $6 \times$ His-tag (Fig. 1A,B) were expressed and purified from Escherichia coli (see Materials and Methods). The truncation constructs encompass the main predicted structural motifs and are named after the predicted motifs that are retained. It should be noted that the recombinant full-length protein does not contain the predicted mitochondrial import signal (first 18 amino acids). The purity and relative sizes of the recombinant proteins were analyzed by SDS-PAGE and Coomassie Blue staining (Fig. 1C). The observed molecular weights of all proteins were consistent with their predicted molecular weights, although most truncations migrate slightly higher on the gel owing to their charges. Recombinant proteins showed degradation products and minor contaminants; however, this did not seem to affect our studies of protein-RNA interaction. Relevant experiments to this effect have been included (see below).

\section{Evaluation of the affinity of KREPA4 variants for gRNA}

An electrophoretic mobility shift assay (EMSA) was performed to determine the affinity of KREPA4 and its deletion variants for gA6[14] gRNA, which specifies the first editing site of the ATPase subunit 6 (A6) pre-mRNA (Koslowsky et al. 1992). A fixed amount of protein (full-length KREPA4 or a deletion mutant) was incubated with increasing concentrations of radiolabeled gA6[14] gRNA, which resulted in the formation of a single slow migrating species that most 
A

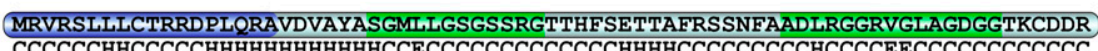
CCCCCCHHCCCCCHHHHHHHHHHHHCCECCCCCCCCCCCCCHHHHCCCCCCCCCHCCCCEECCCCCCCCCCCC

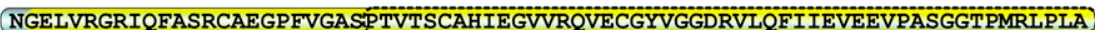
CHHHHHHHHHHHHHHHCCCCCCCCEE EEEEEE EEEEEE EEEEECCCEEEEEEEEEE CCCCCCCCCEEEEE

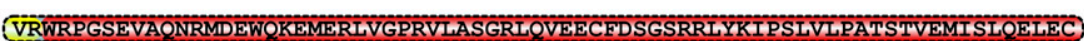
EEECCCHHHHHHHHHHHHHHHCCCCEEEEEEEEEEEEEECCCCCCEEEEEEEEECCCCEEEEEEEECCCC

$\mathbf{B}$

Full length (residues 19-218)

FL minus LCR1 (residues 41-218)

FL minus both LCRs (residues 68-218)

Predicted OB-fold (residues 98-218)

Predicted S1 (residues 75-148)

LCRs + S1 (residues 25-148)

C-terminal (residues 150-218)

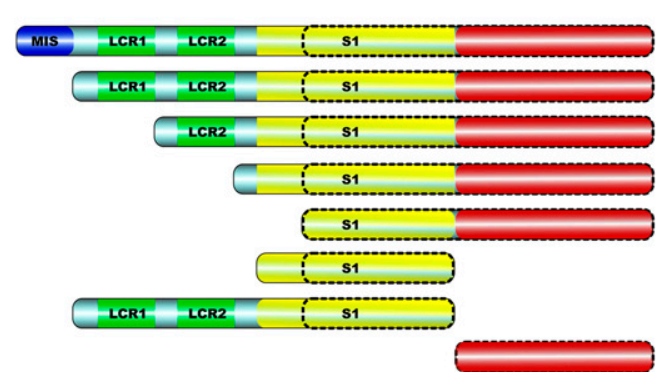

C

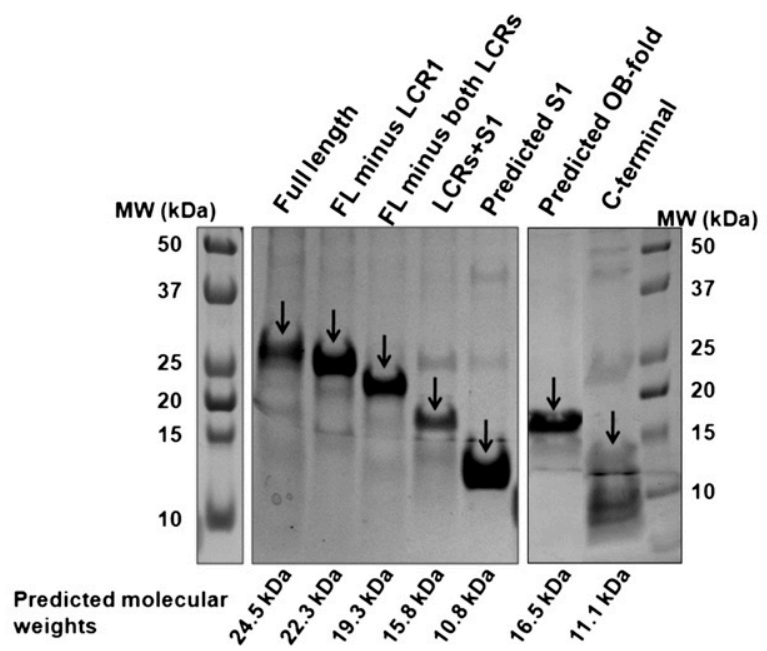

FIGURE 1. Recombinant KREPA4 proteins. (A) Complete amino acid sequence of KREPA4 is shown with the putative mitochondrial import signal sequence highlighted in blue, the predicted low compositional complexity regions in green, and the putative S1 motif in yellow. The predicted OB-fold is depicted by a dashed box and the C-terminal end is highlighted in red. The predicted secondary structure of KREPA4 is denoted below the primary amino acid sequence. $\mathrm{H}$ stands for $\alpha$ helix, E for $\beta$ sheet, and $C$ for coiled regions. $(B)$ The domain structure of the fulllength protein is represented schematically at the top followed by those of the truncation constructs. The name of each protein truncation construct is indicated on the left, followed by the position number of the residues present. (C) Purified, recombinant His-tagged KREPA4 truncation constructs were analyzed by 15\% SDS-PAGE and Coomassie blue staining. The arrows point to the bands of interest. The calculated molecular weights $(\mathrm{kDa}$, including the $6 \times$ His-tag), are indicated below the panel. The molecular weight markers are shown on either side.

likely corresponds to one molecule of protein bound to one molecule of RNA (Fig. 2A). The shifted band was distinct, suggestive of a stable RNA-protein complex while the radiolabeled gA6[14] gRNA in absence of the protein did not change in mobility (data not shown). The results of four independent determinations were analyzed using nonlinear curve fitting methods to estimate the binding affinities (Fig. $2 B)$. From this analysis the $K_{d}$ value of the interaction of fulllength protein with gA6[14] gRNA was determined to be $0.1137 \mathrm{nM}$, which is indicative of significantly higher affinity than that estimated by the protein titration method $\left(K_{\mathrm{d}}\right.$ app $=20 \mathrm{nM}$; see Materials and Methods). This suggests that the full-length KREPA4 binds to gA6[14] gRNA with a very high affinity and that only a fraction of the purified protein was active. The binding affinities of three other truncations were found to be very close to that of the full-length KREPA4. These were the deletion mutants from which either the first or both LCRs were removed with $K_{\mathrm{d}}$ values of $0.1107 \mathrm{nM}$ and 0.1247 $\mathrm{nM}$, respectively. The predicted OB-fold also demonstrated a binding affinity as good as the full-length protein with a $K_{\mathrm{d}}$ value of $0.1185 \mathrm{nM}$. To define a minimal functional protein, the binding affinity of the C-terminal end (last 70 amino acids) deletion variant was calculated and found to be $0.0863 \mathrm{nM}$, which indicates 1.3 times better affinity than the full-length protein. However, the predicted S1 motif with a $K_{\mathrm{d}}$ value of $0.2935 \mathrm{nM}$ exhibited 2.6 times lower affinity than the full-length KREPA4. This decrease in equilibrium binding affinity is considered significant, as previously reported (Setzer et al. 1996). The fusion of LCRs to $S 1$ greatly improved the binding affinity of $S 1$ by $\sim 4.6$ times since LCRs $+\mathrm{S} 1$ truncation had a $K_{\mathrm{d}}$ value of $0.0643 \mathrm{nM}$, which confers even $\sim 1.8$ times higher binding affinity than the full-length protein. Hence LCRs seem to enhance binding affinity of the truncation with a disrupted OB-fold. In conclusion, three truncations emerge as the potential RNA-binding interface of KREPA4. These are the predicted OB-fold domain, the C-terminal end, and the LCRs+S1 constructs. While the predicted OB-fold has the same binding affinity as the full-length protein, LCRs+S1 and the C-terminal end exhibit a better binding affinity than the full-length KREPA4. However, the predicted S1 motif (amino acids 75-148) seems to be the part of KREPA4 with the least contribution in binding function, which possibly suggests that the $\mathrm{S} 1$ motif is not present in KREPA4.

Supershift assays using anti-KREPA4 polyclonal antibodies (Fig. 2C) confirmed that the observed mobility shifts were dependent on KREPA4 and its truncations and did not arise from possible contaminants in the protein preparations.

The two LCRs fused to a $6 \times$ His-tag were not stable when expressed in E. coli, and in the form of individual synthetic peptides, LCR1 and LCR2 (alone or in combination) did not 


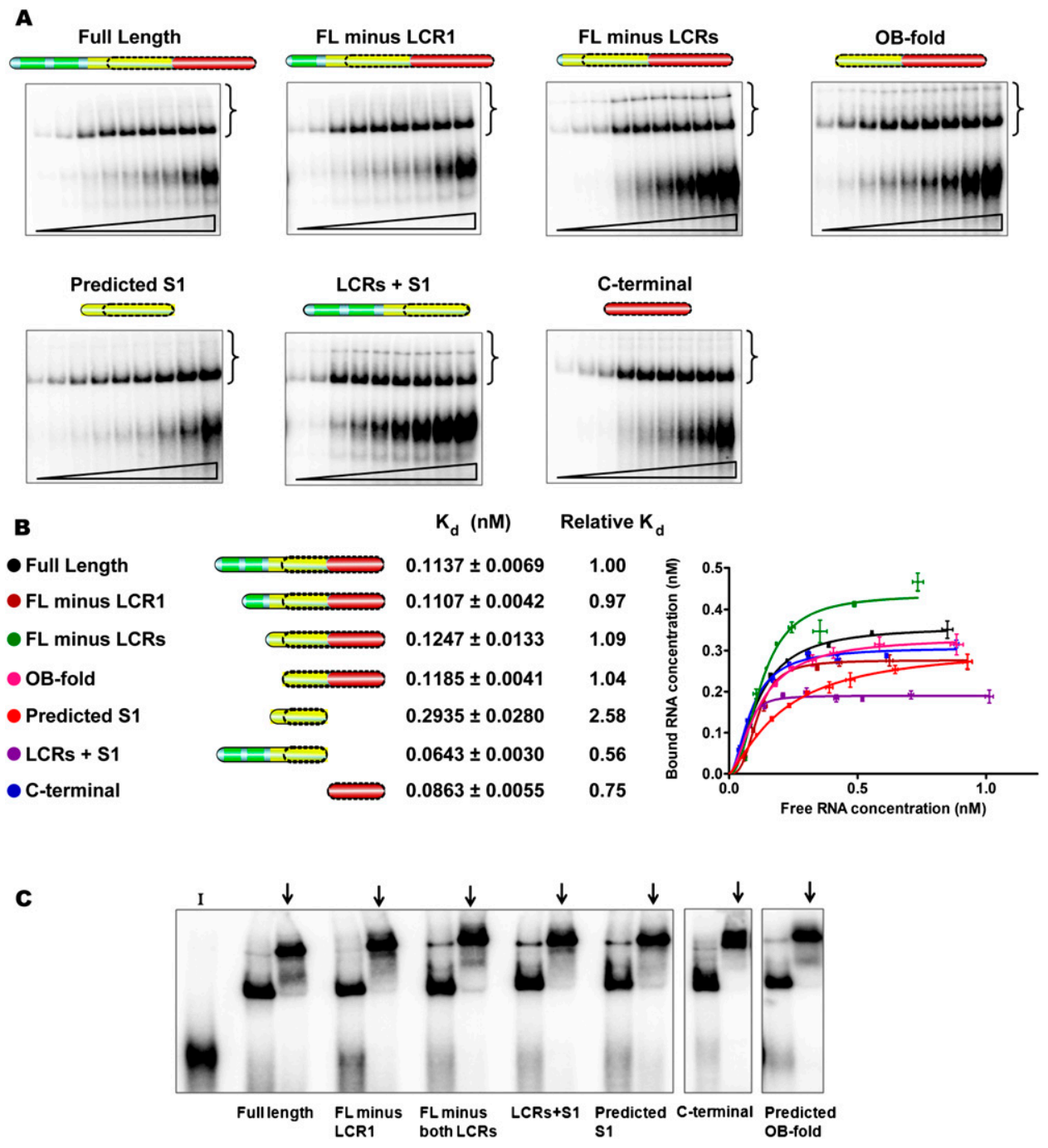

FIGURE 2. gA6[14] gRNA-binding activities of KREPA4 deletion variants monitored by gel-mobility shift analysis. (A) Electrophoretic mobility shift assays (EMSAs) showing binding of a fixed concentration of purified full-length or truncated KREPA4 protein to increasing concentrations of ${ }^{32} \mathrm{P}$ radiolabeled gA6[14] $\Delta$ 16G. Bound and free RNA were resolved on native gels. The wedges represent increasing RNA concentrations (0.1$1.2 \mathrm{nM})$. The gel shifts of radiolabeled RNA with protein are shown by brackets. Each deletion variant is represented schematically above each EMSA. (B) Binding activity in $A$ was quantified using a PhosphorImager and data obtained were analyzed using nonlinear curve fitting methods to estimate the binding affinities. Saturation binding curves indicate the relative amount of RNA bound by a fixed concentration of protein at increasing concentrations of input RNA. Each curve represents the mean and standard error from four separate experiments. $K_{\mathrm{d}}$ values are summarized. $(C)$ Control supershift assay to demonstrate that the binding to gRNA is KREPA4 dependent. Full-length and truncated KREPA4 protein constructs were incubated with radiolabeled gA6[14] gRNA in the absence or presence of anti-KREPA4 antibody. The radiolabeled input RNA is indicated by "I." Lanes showing supershift of protein-RNA complexes are denoted by arrows. Unmarked lanes represent the radiolabeled RNA in the presence of KREPA4 variants in the absence of anti-KREPA4 antibody.

show any binding to gA6[14] gRNA, thereby restricting direct binding analysis of the LCRs with gRNA (data not shown).

In order to further define which parts of the protein play a role in specificity of binding versus affinity, competition experiments were carried out as described in the next section.

\section{Guide RNA-binding specificity of KREPA4}

It has been shown previously that full-length KREPA4 specifically binds the oligo(U) tail of gA6[14] gRNA (Salavati et al. 2006). To identify the KREPA4 motifs that mediate this binding specificity, gel shift assays using radiolabeled gA6[14] gRNA were performed in the presence of increasing amounts of unlabeled competitors (Fig. 3).

Competition assays in the presence of unlabeled gA6[14] gRNA with and without an oligo $(U)$ tail

In the presence of saturating concentrations of radiolabeled gA6[14] gRNA with an oligo(U) tail, the unlabeled homologous RNA functioned very efficiently as a competitor, reducing binding to the labeled RNA by $\sim 50 \%$ for all 
A

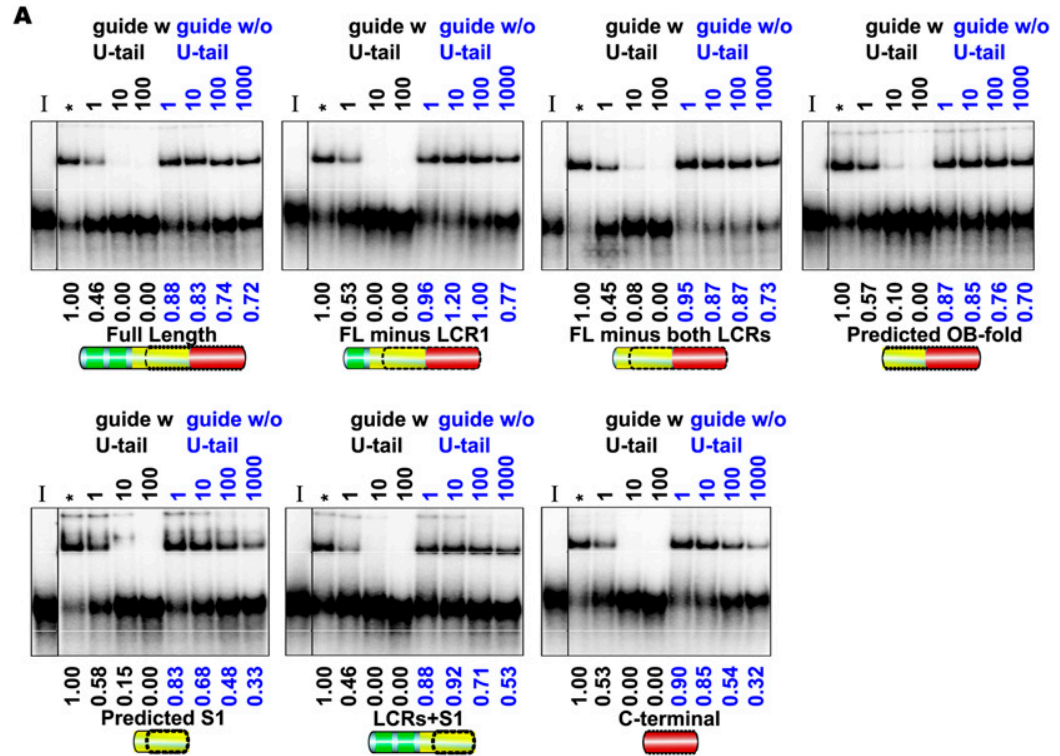

B

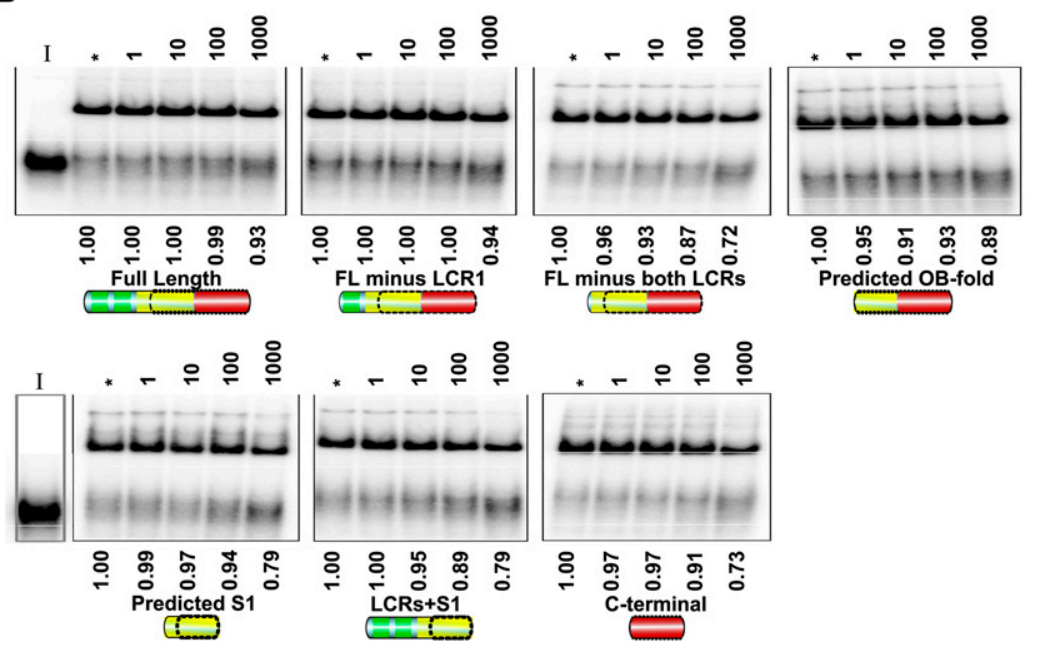

FIGURE 3. Competition assays to determine the specificity of full-length and truncated KREPA4 proteins. (A) Full-length and truncated KREPA4 proteins were incubated with radiolabeled gA6[14] $\Delta 16 \mathrm{G}$ in the absence and presence of increasing concentrations of unlabeled gA6[14] gRNA with or without the U-tail as competitors. "I" indicates the radiolabeled input RNA; asterisk denotes the radiolabeled RNA in the presence of KREPA4 without competitor RNA. Numbers above the panels indicate the fold excess of unlabeled competitor RNAs. Numbers below the panels indicate percent of shift in the presence of competitor RNAs normalized to the shifts in the absence of a competitor $\left(^{*}\right)$. Each deletion variant is represented schematically below each EMSA. (B) Same as A; except that the unlabeled competitor is pBluescript RNA.

proteins at equimolar concentrations, and eliminating binding at higher concentrations of the competitor (Fig. 3A).

While the complex formation by full-length KREPA4 was reduced by $50 \%$ at an equimolar ratio of gA6 [14] gRNA with an oligo(U) tail as a competitor, only $28 \%$ reduction of complex formation could be detected at 1000 times molar excess of gA6[14] gRNA without the oligo(U) tail as a competitor (Fig. 3A). This suggests that the full-length protein displays at least 1000 times greater affinity for $\mathrm{U}$-tailed
gRNA in comparison with the gRNA without the U-tail. This is true for all deletion mutants as well; however, the degree of affinity varies. Hence, the binding seems to be specific for the gRNA oligo(U) tail. However, for all constructs, the competition observed at the highest amount of the gRNA without the U-tail as a competitor could be suggestive of either a low-affinity binding of gA6[14] gRNA without the U-tail by KREPA4 in a nonspecific manner or the presence of a second specific, low-affinity binding site on gA6 [14] gRNA, which is located on the 5 ' stem-loop region of gRNA. In order to address these two possibilities the next set of competition experiments using Bluescript RNA and gRNAs with stemloop modifications were carried out.

\section{Competition assays in the presence of unlabeled Bluescript RNA}

The heterologous Bluescript RNA was by and large inefficient as a competitor, causing only slight competition at the highest concentrations tested, thereby pointing toward the binding specificity of KREPA4 for gRNA with an oligo(U) tail (Fig. 3B). Overall, the gRNA without the $\mathrm{U}$-tail is a much better competitor for all constructs than Bluescript RNA, which implies that the secondary structure of gRNA could play a role in KREPA4 binding, although the $3^{\prime}$ oligo(U) tail is the major binding determinant.

\section{Competition assays in the presence of unlabeled gA6[14] gRNAs with stem-loop modifications}

The competition experiments described above suggested that, although the $3^{\prime}$ oligo(U) tail is the major binding determinant, other gRNA structural elements could have a role in gA6[14] gRNA-KREPA4 interaction. In order to test the contribution of stem-loop elements, we created a set of gRNAs with modifications in either one or both stemloops (Fig. 4A). In the first set of artificial stem-loop constructs, either one or both of the original stem-loops of gA6[14] gRNA were swapped by the respective stem-loops of another gRNA, gCyb-558 (Riley et al. 1994). This kind of modification generated gA6[14] gRNA variants with altered sequences as well as differently sized stem-loop elements. A second set of artificial stem-loop constructs was created by 


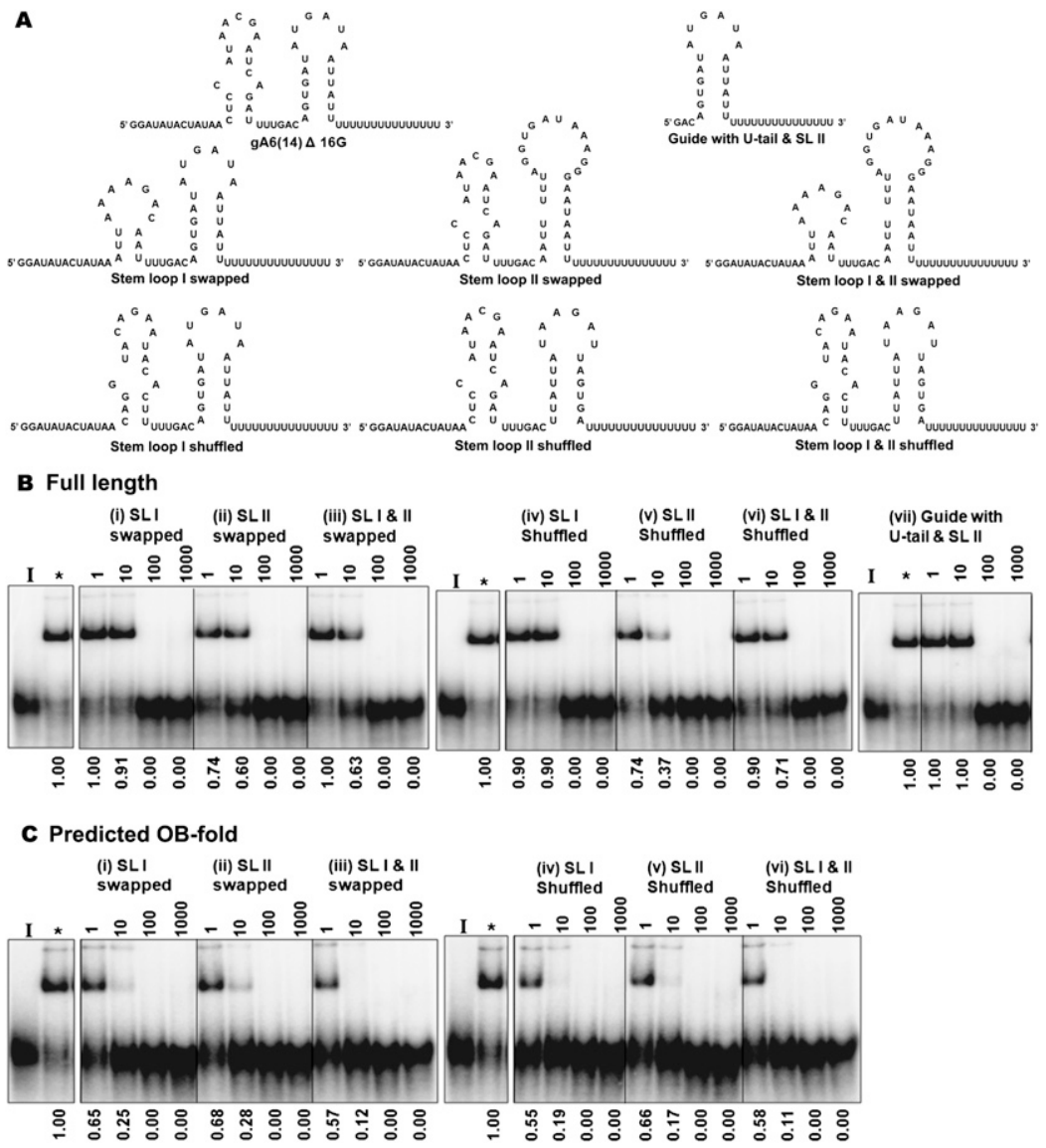

FIGURE 4. Competition assays to determine the role of gRNA structural elements in binding. (A) Schematic representation of a panel of gA6[14] gRNA variants. gA6[14] $\Delta 16 \mathrm{G}$ has been depicted first, followed by a truncated version lacking stem-loop (SL) I, and variants with stem-loop modifications are shown next. (B) Full-length KREPA4 was incubated with radiolabeled gA6[14] $\Delta 16 \mathrm{G}$ in the absence and presence of increasing concentrations of unlabeled competitors as indicated. "I" indicates the radiolabeled input RNA; asterisk denotes the radiolabeled RNA in the presence of KREPA4 without competitor RNA. Numbers above the panels indicate the fold excess of unlabeled competitor RNAs. Numbers below the panels indicate percent of shift in the presence of competitor RNAs normalized to the shifts in the absence of the competitor $\left.{ }^{*}\right)$. (C) Same as $B$; except that the predicted OB-fold truncation was used instead of full-length KREPA4.

flipping the base pairs in the stem regions of gA6[14] gRNA and by random shuffling of bases in the loops. This kind of modification generated gA6[14] gRNA variants with altered sequences, albeit retaining the original stem-loop conformations.

When any of these gA6[14] gRNAs with stem-loop modifications were used as the unlabeled competitors (Fig. 4B), it was observed that the complex formed between fulllength KREPA4 and radiolabeled gA6[14] gRNA could not be competed away as efficiently as by the wild-type gA6[14] gRNA competitor itself (Fig. 3A). This clearly demonstrates that the stem-loop elements are involved in KREPA4gA6[14] gRNA interaction, although not to the same extent as the oligo(U) tail, which is the major binding determinant. It should be noted that the second set of artificial stem-loop constructs with shuffled stem-loops were designed in a way that most likely preserves the conformation and only alters the sequence of gA6[14] gRNA stem-loops. Since the gA6[14] gRNAs with shuffled stem-loops are also not able to compete away the bound complex as efficiently as the wildtype gA6[14] gRNA competitor, it emerges that the interaction of KREPA4 with gA6[14] gRNA is sequence-specific. Second, it seems that the interaction of the full-length KREPA4 with stem-loop I is of greater significance than its interaction with stem-loop II. This is evident from the fact that any kind of modification in stem-loop I renders gA6[14] gRNA less efficient as a competitor than gA6[14] gRNA with modification in stem-loop II alone (Fig. 4B, cf. i and ii, iv and v). Also, a truncated version of gA6[14] gRNA from which stem-loop I has been deleted is not able to compete as efficiently as the wildtype gA6 [14] gRNA competitor itself (Fig. $4 \mathrm{~B}$, panel vii). This further corroborates the idea that the interaction of KREPA4 with stem-loop I is preferred.

It is interesting to note that, while the full-length protein showed a reduced affinity toward all gA6[14] variants with modified stem-loops, the predicted OBfold demonstrated almost as much affinity for the variants as for the wild-type gA6[14] gRNA (Fig. 4C). At equimolar concentration, each of the competitors with a stem-loop modification was able to produce close to $50 \%$ reduction in binding of the labeled gA6[14] gRNA to the OB-fold and almost eliminate the binding at 10 times molar excess, in a manner similar to the wild-type gA6[14] gRNA competitor. This possibly suggests that the OB-fold truncation that lacks the two LCRs loses the ability to recognize any modifications in the stem-loop elements. Hence, it seems that LCRs are the regions responsible for mediating a sequence-specific interaction of KREPA4 with the gA6[14] gRNA stem-loop elements.

\section{Competition assay in the presence of unlabeled uridylated nonguide $R N A s$}

In order to more rigorously define the roles of the oligo(U) tail and stem-loop elements as binding determinants, we designed two types of uridylated nonguide RNAs. One was a 49-nucleotide (nt)-long random RNA with a single predicted stem-loop element and an oligo(U) tail (15 U's). The other was a 70-nt-long random RNA with two predicted GCrich stem-loops and an oligo(U) tail (15 U's) (Fig. 5A). 
A
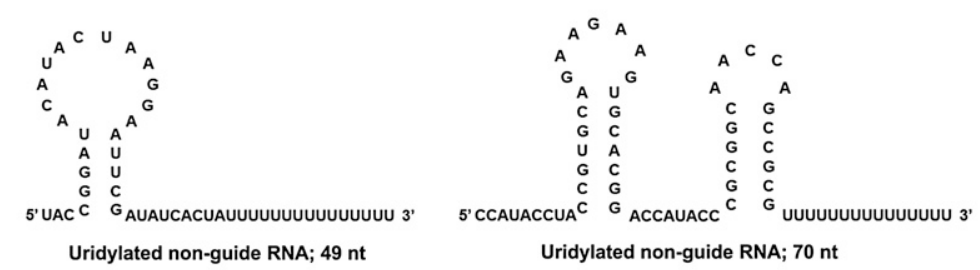

B (i) Full length KREPA4

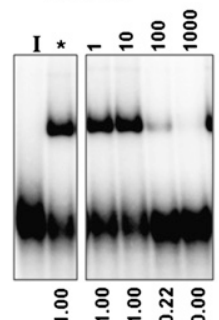

Competition with uridylated non-guide RNA; 49 nt

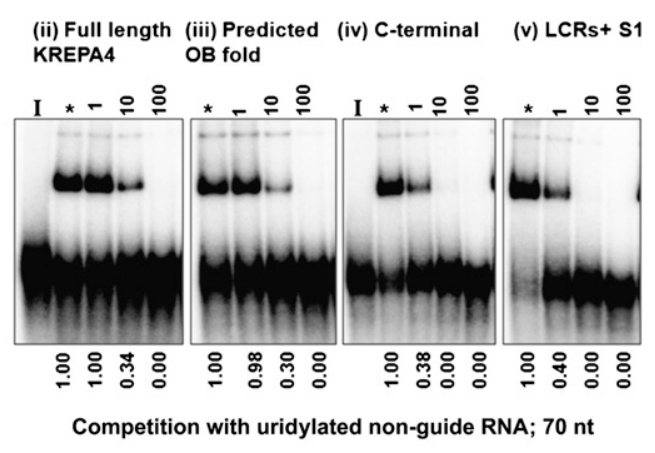

FIGURE 5. Competition assays to determine the role of the gRNA oligo(U) tail versus stemloop elements in binding. (A) Schematic representation of uridylated nonguide RNAs; one is 49nt-long with a single predicted stem-loop and an oligo(U) tail; the other is 70-nt-long with two predicted GC-rich stem-loop elements and an oligo(U) tail. (B) $i$, Full-length KREPA4 was incubated with radiolabeled gA6[14] $\Delta 16 \mathrm{G}$ in the absence and presence of increasing concentrations of unlabeled 49-nt-long uridylated nonguide RNA as the competitor. "I" indicates the radiolabeled input RNA; the asterisk denotes the radiolabeled RNA in the presence of KREPA4 without competitor RNA. Numbers above the panel indicate the fold excess of unlabeled competitor RNAs. Numbers below the panel indicate percent of shift in the presence of competitor RNAs normalized to the shifts in the absence of a competitor $\left(^{*}\right)$. $i i, i i i, i v$, and $v$ are the same as $i$, except that the unlabeled competitor is the 70-nt-long uridylated nonguide RNA. The proteins employed in these competitions have been indicated above the panels.

uridylated RNA with GC-rich stemloops was not as efficient a competitor (Fig. 5B, panel iii). This possibly suggests that the OB-fold truncation, in spite of lacking the two LCRs and thus possibly not being able to interact with the stemloop elements, is still able to differentiate between guide-like AU-rich RNA elements versus non-guide-like GC-rich RNA elements. However, this does not seem to be the case with C-terminal and LCRs+S1 proteins as they bind to the 70-nt-long uridylated competitor as efficiently as to the wild-type gA6[14] gRNA competitor (Fig. 5B, panels iv,v). Considering that LCRs possibly mediate a sequence-specific interaction with the guide stem-loop elements, the inability of LCRs+S1 truncation to differentiate between wild-type gA6[14] gRNA and the 70-nt-long uridylated RNA could only be explained by the presence of a truncated OB-fold domain in LCRs+S1 protein. It could be possible that, only in the presence of an intact OB-fold domain, the specific interaction of LCRs with stem-loop structures is enabled. The binding affinities of $\mathrm{C}$-terminal and LCRs + S1 proteins for gA6[14] gRNA are even better than that of the full-length protein, but they seem not to retain the specificity for AU-rich gRNAs. In com-

Hence, both RNAs had an oligo(U) tail similar to gRNAs but differed from each other in length and possibly in stem-loop secondary structure. The 70-nt-long RNA was designed to have all the features of a typical gRNA except that it was not AU rich. Both of the predicted stem-loops were GC rich. For the complex formed between full-length KREPA4 and radiolabeled gA6[14] gRNA, the 70-nt-long RNA with GC-rich stem-loops and an oligo(U) tail was a much more efficient competitor in comparison with the shorter 49-nt-long uridylated RNA (Fig. 5B, cf. i and ii). This was expected and reaffirmed the hypothesis that the oligo $(\mathrm{U})$ tail is not the sole binding determinant and that the contribution of stemloop elements in gRNA-binding of KREPA4 is significant. Also, similar to the gA6[14] gRNA variants with stem-loop modifications, the 70-nt-long uridylated RNA was also not able to compete as well as the wild-type gA6[14] gRNA competitor itself (Fig. 5B, cf. panel ii and Fig. 3A). This again demonstrates that the interaction of KREPA4 with gA6[14] gRNA is sequence specific and potentially prefers AU-rich sequences.

While gA6[14] gRNA variants with stem-loop modifications bind to the OB-fold protein with almost the same affinity as the wild-type gA6[14] (Fig. 4C), the 70-nt-long parison wirh the full-length or OB-fold proteins, these truncations (i.e., C-terminal and LCRs+S1) generally demonstrate a higher degree of nonspecific binding to almost any competitor (gA6[14] gRNA without a U-tail; heterologous bluescript RNA, Fig. 3; CYb pre-mRNA) (data not shown). This implies that truncations lacking an intact OB-fold show a reduced ability to discriminate between guide-like versus non-guide-like RNAs.

Taken together, we conclude that, while the gRNA oligo(U) tail is the major binding determinant in the KREPA4-gA6[14] gRNA interaction, the gRNA secondary structure also plays a definite role, albeit to a smaller extent. The gRNA stem-loop elements are potentially recognized by the arginine-glycinerich LCRs at the $\mathrm{N}$ terminus of KREPA4 in a sequence-specific manner while the predicted OB-fold seems to interact mostly with the guide oligo(U) tail. Overall, an intact OB-fold together with the LCRs appears to be necessary for the full manifestation of the preference of KREPA4 for gRNAs. Within the boundaries of the predicted OB-fold, the C-terminal end is independently capable of mediating high-affinity binding with gRNA in vitro; hence this region most likely encompasses a significant part of the ligand-binding interface of the KREPA4 OB-fold. 


\section{KREPA4 has gRNA/pre-mRNA annealing activity}

Considering the high affinity with which KREPA4 binds to gRNA, we wanted to determine whether recombinant KREPA4 is able to facilitate gRNA/pre-mRNA hybrid formation, which is the first step of the RNA editing reaction (Blum et al. 1990). Hence, an RNA annealing assay was performed in which A6U5, a pre-edited mRNA derived from the first editing site of the Trypanosoma brucei A6 mRNA, and its cognate gRNA, gA6[14] gRNA, were used in a 1:1 molar ratio. A gRNA/pre-mRNA hybrid structure that is formed due to annealing of the two RNAs has a reduced mobility as compared with single-stranded A6U5 RNA in a native polyacrylamide gel. Figure $6 \mathrm{~A}$ shows a representative experiment. Figure 6A, lanes 2 and 10, show a low level of self-annealing between gRNA and pre-mRNA in the absence of KREPA4. The addition of full-length, recombinant KREPA4 stimulates the formation of the annealed product in a concentration-dependent manner (Fig. 6A, lanes 11-15). At the highest concentration of full-length KREPA4 (3.1 nM), gRNA/pre-mRNA annealing was $\sim 2.8$ times stronger (Fig. 6A, lane 15) than the level of self-annealing (Fig. 6A, lanes 2 and 10). Addition of BSA as a negative control (Fig. $6 \mathrm{~A}$, lane 9) resulted in an annealed product only as much as the self-annealing product and no annealing was detected in the presence of a noncognate gRNA (gCYb) (Fig. 6A, lane 16). The predicted OB-fold truncation, which possessed the same binding affinity toward gA6[14] gRNA as the full-length protein, was next tested for its ability to stimulate dsRNA formation. Addition of increasing amounts of the OB-fold truncation was able to stimulate annealing to a similar extent as the full-length KREPA4 (Fig. 6A, lanes 3-7) and the specific annealing was $\sim 2.3$ times stronger than self-annealing at the highest concentration of protein tested ( $2 \mathrm{nM})$ (Fig. 6A, lane 7). Again, no annealing was detected in the presence of noncognate gCYb (Fig. 6A, lane 8). It should be noted that, while the OB-fold-mediated annealing signal visually appears to be more robust than that produced by the full-length KREPA4, quantification of the annealed product over total radiolabeled species in each lane resulted in higher numbers for full-length KREPA4.

As a control for the annealing experiment, direct binding of KREPA4 to radiolabeled edited and pre-edited A6 mRNA was also tested. While KREPA4 is completely saturated by 1.0 nM of gA6[14] gRNA, the same concentration of the protein did not show any binding to even $10 \mathrm{nM}$ of edited or preedited A6 mRNA (Fig. 6B, inset). Hence, KREPA4 did not show any stable binding to A6 mRNA under the reaction conditions tested and, therefore, most likely entered the annealing reaction as a gRA-KREPA4 complex.

\section{KREPA4 annealing activity is dependent on its oligo(U) tail interaction}

The above result demonstrates that the predicted OB-fold domain individually possesses RNA annealing activity. Since the predicted OB-fold domain lacks the LCRs that potentially mediate a sequence-specific interaction with the stem-loop elements, it seems that the RNA annealing function of KREPA4 is more or less independent of the recognition of stem-loop secondary structure elements by the LCRs and relies more upon the OB-fold-mediated, high-affinity interaction with the gRNA oligo(U) tail. This hypothesis is further supported by an annealing experiment in which gA6[14] gRNA without the U-tail was used in an equimolar ratio with A6U5 pre-mRNA (Fig. 6B). Increasing concentrations of neither the full-length protein nor the OB-fold truncation could stimulate annealing between A6U5 premRNA and gA6[14] gRNA without the U-tail to any significant extent. This clearly demonstrates that the gRNA oligo(U) tail is required for KREPA4 to stimulate dsRNA formation and the RNA-binding and annealing functions of KREPA4 are correlated.

\section{KREPA4 stimulates annealing of CYb pre-mRNA and 37-mer CYb gRNA}

We next wanted to investigate if annealing of other cognate pairs of gRNAs and mRNAs were also facilitated by KREPA4. To this effect, annealing reactions containing the $\mathrm{CYb}$ premRNA, which is edited only in its $5^{\prime}$ region exclusively by insertion events (Igo et al. 2002), and its cognate guide, the natural CYb gRNA (gCYb [558]), were examined in the presence of increasing concentrations of KREPA4. No annealing was detected even after using up to five times molar excess of the natural CYb gRNA and even by heating and cooling down the substrates together (data not shown). This was not surprising considering previous reports of the natural CYb gRNA not supporting in vitro editing activity (Igo et al. 2002). Also, when used as a competitor, the natural $\mathrm{CYb}$ gRNA could not significantly reduce the binding of radiolabeled gA6[14] gRNA to KREPA4, even at 1000 times molar excess (data not shown). Hence, we substituted the natural CYb gRNA by an artificially enhanced 37 -mer CYb gRNA (Fig. 7A), which also specifies insertion of two uridines into editing site 1 and has been shown to support in vitro endonuclease activity (Piller et al. 1997; Salavati et al. 2002). The 37-mer CYb gRNA used here is highly similar to the enhanced CYb gRNA (gCYb[558] USD-2A-42nt), which in a previous study by Miller et al. (2006) has also been shown to support in vitro editing activity. The 37-mer CYb gRNA has been modified so that it accurately and more extensively base-pairs with the CYb pre-mRNA over a stretch of $30 \mathrm{nt}$, thereby resulting in extended complementarity and a more stable gRNA-mRNA interaction.

When increasing concentrations of either full-length KREPA4 or the predicted OB-fold truncation were added to reactions containing $\mathrm{CYb}$ pre-mRNA and the 37 -mer $\mathrm{CYb}$ gRNA, a significant stimulation of annealing was observed (Fig. 7B), although not to the same extent as that observed with A6U5 pre-mRNA and gA6[14] gRNA. Considering that 
A

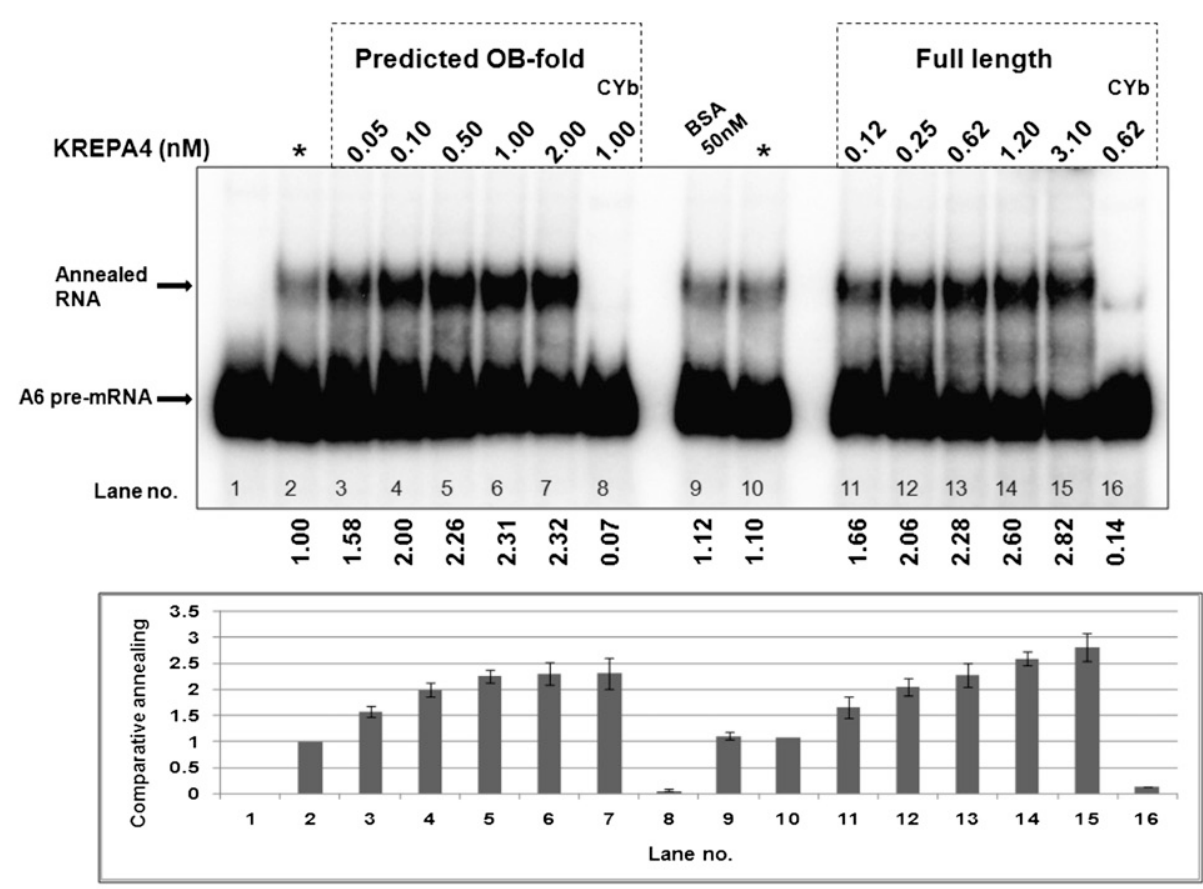

$\mathbf{B}$
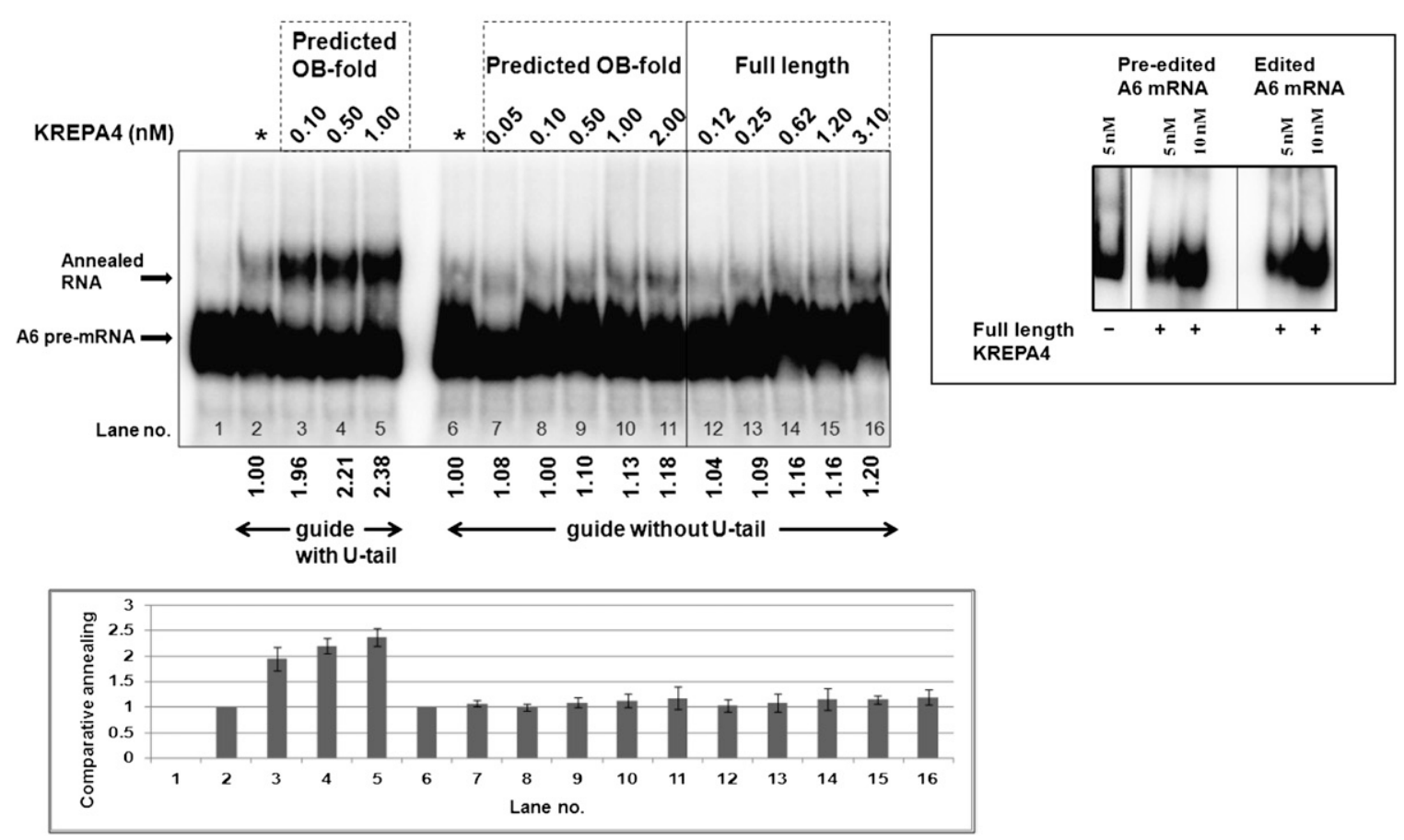

FIGURE 6. Recombinant KEPA4 stimulates the annealing of A6U5 pre-mRNA to cognate gRNA in vitro and requires the gRNA oligo(U) tail for this function. (A) Annealing assay of radiolabeled A6U5 pre-edited mRNA and gA6[14] $\Delta 16 \mathrm{G}$ at the indicated protein concentrations. The arrows indicate the radiolabeled A6U5 pre-edited mRNA and the annealed gRNA-pre-mRNA products. Lanes are numbered: (lane 1) the radiolabeled A6U5 pre-mRNA alone; (lanes 2,10) self-annealing in the absence of protein. Control reactions used $50 \mathrm{nM} \mathrm{BSA}$ and the noncognate CYb gRNA. Numbers below the panel indicate the percentage of annealed product in the presence of protein relative to self-annealing in the absence of protein, with the percent annealed product in the absence of protein being set to 1. Graphical representation of the same with error bars depicting standard deviation from four independent experiments. (B) Same as A except that gA6[14] gRNA without the U-tail was used as indicated. (Lane 2) Self-annealing in the absence of protein between radiolabeled A6U5 pre-mRNA and gA6[14] gRNA with the U-tail; (lane 6) the same between radiolabeled A6U5 pre-mRNA and gA6[14] gRNA without the U-tail. (Inset) Inability of full-length KREPA4 to bind to the indicated concentrations of radiolabeled pre-edited and edited A6 mRNA. 

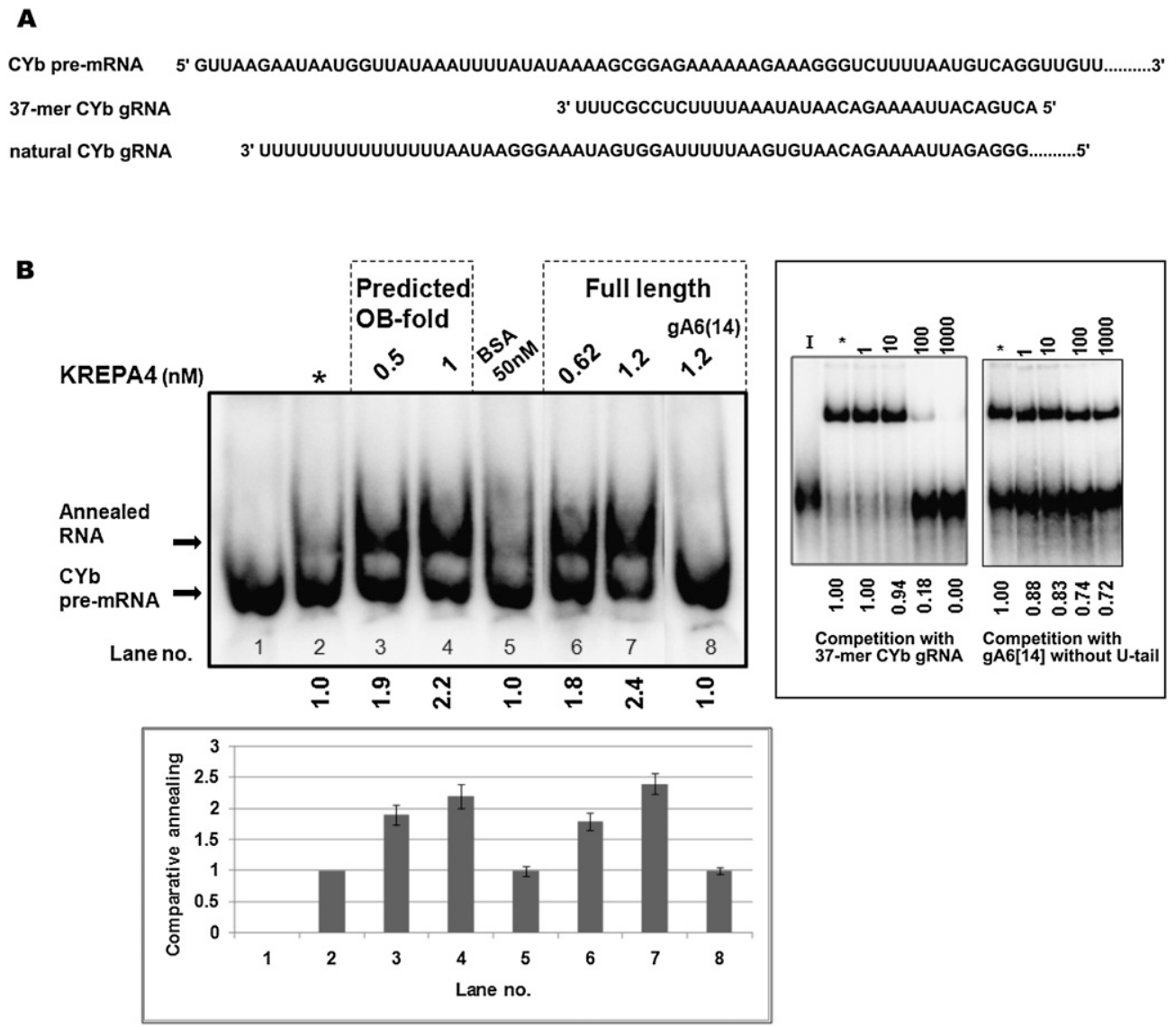

FIGURE 7. Recombinant KEPA4 stimulates the annealing of CYb pre-mRNA to 37-mer CYb gRNA in vitro. (A) A partial sequence of CYb premRNA is shown in the $5^{\prime}-3^{\prime}$ direction. Complete sequence of 37-mer CYb gRNA in the $3^{\prime}-5^{\prime}$ direction is aligned with the CYb pre-mRNA sequence to show complementarity. A partial sequence of natural CYb gRNA (gCYb[558]) has also been shown in the $3^{\prime}-5^{\prime}$ direction. $(B)$ Annealing assay of radiolabeled $\mathrm{CYb}$ pre-edited mRNA and 37-mer CYb gRNA at the indicated protein concentrations. The arrows indicate the radiolabeled $\mathrm{CYb}$ pre-edited mRNA and the annealed gRNA-pre-mRNA products. Lanes are numbered: (lane 1) the radiolabeled CYb pre-mRNA alone; (lane 2) self-annealing in the absence of protein. Control reactions used $50 \mathrm{nM}$ BSA and the noncognate gA6[14] gRNA. Numbers below the panel indicate the percentage of annealed product in the presence of protein relative to self-annealing in the absence of protein, with the percent annealed product in the absence of protein being set to 1. Graphical representation of the same with error bars depicting standard deviation from three independent experiments. (Inset) The binding of full-length KREPA4 with radiolabeled gA6[14] $\Delta 16 \mathrm{G}$ in the absence $\left({ }^{*}\right)$ and presence of increasing concentrations of unlabeled competitors as indicated.

the 37-mer CYb gRNA does not contain a typical stretch of the oligo(U) tail, in the absence of which annealing activity of KREPA4 is significantly reduced (Fig. 6B), it was surprising to observe enhancement of annealing in this case. This could be explained by the considerably higher binding affinity of KREPA4 for the 37-mer CYb gRNA in comparison with gA6[14] gRNA without the U-tail (37-mer CYb gRNA being a better competitor than gA6[14] gRNA without the U-tail in the competition assay) (shown in Fig. 7B, inset). The 37mer CYb gRNA, although lacking a typical oligo(U) tail, still contains a U-rich region at its $3^{\prime}$ end that might facilitate KREPA4 binding. This hypothesis is supported by the experimental observation that KREPA4 seems to have the same binding affinity for the 37-mer CYb gRNA lacking a typical oligo(U) tail as it does for the 49-nt-long nonguide RNA with a conventional oligo(U) tail (cf. the competitions in Fig. 7B, inset, and Fig. 5B, panel i). In addition, although the total number of complementary base pairs between A6U5 pre-mRNA/gA6[14] gRNA and CYb pre-mRNA/37-mer $\mathrm{CYb}$ gRNA are the same (about 30 base pairs [bp], including noncanonical G:U base pairing), there is a considerable difference in the percentage of GC base pairs between the two substrates. While the A6U5 pre-mRNA/gA6[14] gRNA duplex has only $13 \%$ GC base pairs, the CYb pre-mRNA/37mer CYb gRNA duplex contains 33\% GC base pairs, thereby rendering this dsRNA more stable. Furthermore, stimulation of annealing between $\mathrm{CYb}$ pre-mRNA and 37-mer $\mathrm{CYb}$ gRNA by KREPA4 could only be achieved at a 1:2 ratio of mRNA:gRNA as opposed to the 1:1 ratio between A6U5 premRNA and gA6[14] gRNA. In conclusion, although we were unable to determine the annealing function of KREPA4 with respect to the natural CYb gRNA, the protein does seem to be able to facilitate annealing of other cognate pairs of gRNAs and mRNAs. 


\section{KREPA4-mediated annealing is specific to RNA editing substrates}

Next we addressed whether KREPA4 could also mediate RNA annealing of any two random complementary RNAs. Two synthetic RNAs predicted to form an 18-bp stem element and 12-base 5' overhangs (Fig. 8A) were used for the annealing assay in a 1:2 molar ratio. Addition of increasing amounts of either full-length KREPA4 or the predicted OB-fold protein resulted in only a marginal stimulation of dsRNA formation (Fig. 8B). The specific annealing in the presence of protein was not $>1.5$ times in

$\mathbf{A}$

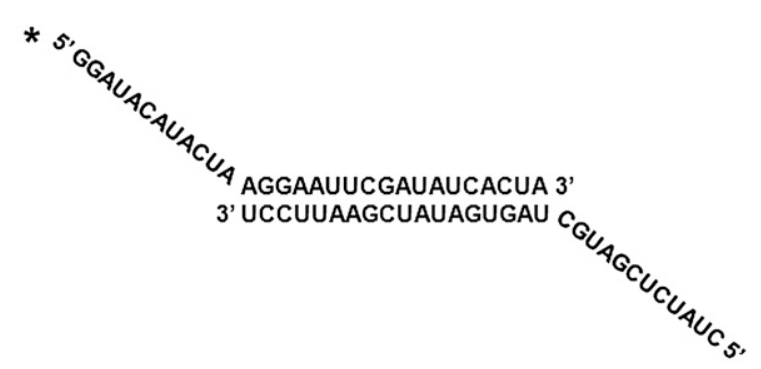

B
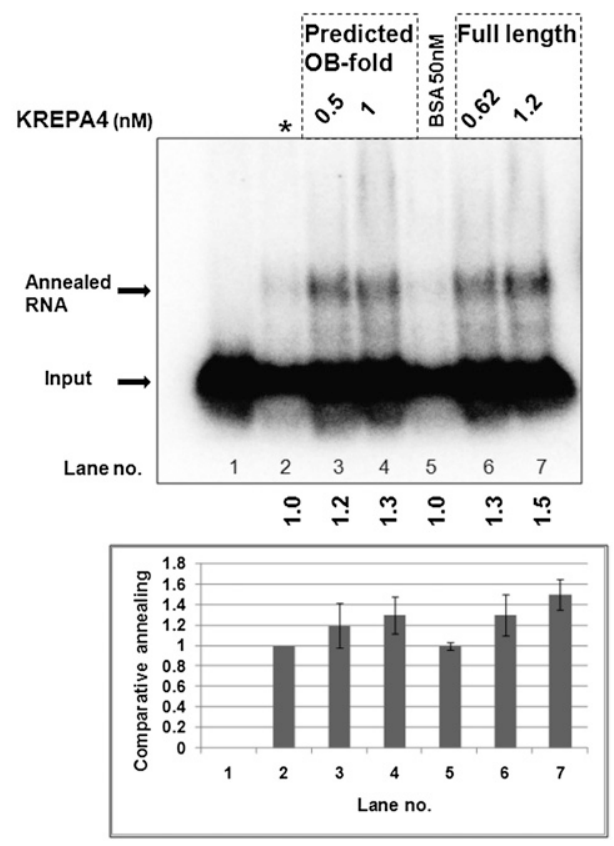

FIGURE 8. Annealing function of KREPA4 is specific for RNA editing substrates. (A) Schematics of synthetic complementary RNA reactants capable of forming an 18-bp duplex region with 12-nt $5^{\prime}$ overhangs. The radiolabeled RNA has been indicated by *. (B) Representative annealing assay in the presence of the indicated protein concentrations. (Lane 1) The radiolabeled input RNA alone; (lane 2) self-annealing in the absence of protein. (Lane 5) A control reaction with $50 \mathrm{nM}$ BSA. Numbers below the panel indicate the percentage of annealed product in the presence of protein relative to self-annealing in the absence of protein, with the percent annealed product in the absence of protein being set to 1 . Graphical representation of the same with error bars depicting standard deviation from three independent experiments. comparison to self-annealing. This is almost half the enhancement obtained with A6U5 pre-mRNA and gA6[14] gRNA. Thus, KREPA4 does not seem to stimulate annealing of nonediting RNA substrates to the same extent as it does for cognate gRNA-pre-mRNA pairs.

\section{DISCUSSION}

In this study we have characterized the molecular interactions involved in KREPA4 gRNA-binding and demonstrated an annealing function associated with this protein. The predicted OB-fold of KREPA4 mediates a high-affinity binding interaction with gRNA and the RNA annealing activity of the protein also resides within the OB-fold. The full-length recombinant protein binds its substrate in vitro with a $K_{\mathrm{d}}$ value of $\sim 0.1137 \pm 0.0069 \mathrm{nM}$, which is indicative of a very tight binding and is well within the range reported for other known OB-fold proteins - for instance, the binding of yeast single-stranded telomeric DNA by Cdc13 (Lin and Zakian 1996; Nugent et al. 1996). This is also in agreement with the recent report on the 3D structural characterization of the RNA editing machinery in T. brucei, which suggests that the 20S editosomes contain an RNA-binding site, which binds gRNA, pre-mRNA, and gRNA/pre-mRNA hybrid molecules with nanomolar affinity (Golas et al. 2009).

KREPA4 has been shown to exhibit a strong preference for poly(U) RNA (Salavati et al. 2006), and our study also confirms that the gRNA oligo(U) tail is the major binding determinant. However, our results also indicate that the gRNA secondary structure plays a distinct role in binding. On the basis of results presented here, a working model for the KREPA4-gRNA interaction can be proposed as follows (Fig. 9). The predicted OB-fold of KREPA4 mediates a highaffinity binding to the gRNA oligo(U) tail, which appears to be the major-but not the sole-binding determinant. The gRNA stem-loop elements seem to play a crucial role in binding, albeit not to the same extent as the oligo(U) tail. It is the arginine/glycine-rich LCRs at the $\mathrm{N}$ terminus of KREPA4 that recognize the gRNA secondary structure and seem to mediate a sequence-specific interaction with the gRNA stem-loop elements. This is apparent from our results, which showed that while the full-length protein retained the preference for stem-loop secondary structures, deletion of the LCRs resulted in loss of this specificity, thereby suggesting that LCRs are the regions essential for the specific recognition of stem-loops. In comparison with wild-type gA6 [14] gRNA, KREPA4 seemed to have reduced affinity for gA6[14] gRNA variants with modifications that potentially disrupted the gRNA stem-loop sequences, while still preserving the structure. This indicates that the LCRs not only recognize the gRNA secondary structure but also mediate a sequencespecific interaction with the stem-loop elements. This in turn suggests that KREPA4 might show a preference for some gRNAs over the others, i.e., it might bind to a few gRNAs with a higher affinity than others. However, in a previous report 


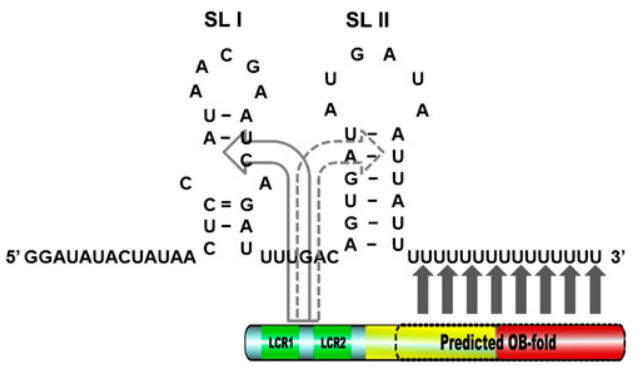

FIGURE 9. Proposed model for the interaction of KREPA4 with gA6[14] gRNA. The predicted OB-fold of KREPA4 mediates a highaffinity binding to the gRNA oligo(U) tail, which is the major binding determinant and this contact is stabilized by the LCRs through sequence-specific interactions with the guide stem-loop elements. The interaction of KREPA4 with stem-loop I (SL I) is preferred over that with stem-loop II (SL II) and is indicated by solid versus dashed lines, respectively. The high-affinity interaction with the gRNA U-tail is indicated by filled arrows.

by Salavati et al. (2006), KREPA4 knockdown has been shown to cause a $60 \%-80 \%$ reduction in the in vivo levels of most of the edited mRNAs tested. But this most likely is due to the loss of the $20 \mathrm{~S}$ editosome and, consequentially, loss of RNA editing upon KREPA4 down-regulation, rather than due to a direct inhibition of KREPA4 gRNA binding function.

Furthermore, among the two stem-loops, KREPA4 seems to have a more significant interaction with stem-loop I versus stem-loop II. This conclusion can be made on the basis of competition experiments, which show that any kind of modification in stem-loop I renders gA6[14] gRNA less efficient as a competitor than gA6[14] gRNA with modification in stem-loop II alone. Overall, we postulate that KREPA4 recognizes the gRNA U-tail via its OB-fold domain and this contact is stabilized by the LCRs through sequencespecific interactions with the guide stem-loop elements. The proposed KREPA4-gRNA-binding model is more similar to the RBP16-gRNA interaction, in which the U-tail is the primary binding determinant and the cold shock domain (CSD) of RBP16 mediates sequence-specific binding to gRNA oligo(U) tails, while the RGG domain stabilizes this initial contact through nonspecific interactions with the guide secondary structure (Pelletier et al. 2000). In contrast, MRP1/MRP2 binding to gRNAs is dependent on recognition of a stem-loop secondary structure element, while interaction with the oligo $(U)$ tail is not significant (Schumacher et al. 2006).

OB-folds are characterized by a conserved architecture where five/six $\beta$ strands form a closed $\beta$ barrel capped by a connecting helix located between the third and fourth $\beta$ strands (Theobald et al. 2003). However, variations are abundant with $\beta$ strand extensions and differently sized loops. OB-folds tend to use a common ligand-binding interface centered around $\beta$ strands 2 and 3. Together with surrounding loops, they form a single-stranded nucleic acid recognition surface, where a few nucleotides often bind through aromatic stacking, hydrogen bonding, hydrophobic packing, and polar interactions (Theobald et al. 2003; Bochkarev and Bochkareva 2004). The secondary structure prediction of KREPA4 undertaken in this study combined with our binding data conforms to the presence of an OBfold domain at the $\mathrm{C}$ terminus of KREPA4. The boundaries of the KREPA4 OB-fold, as predicted in a previous study (Worthey et al. 2003), have been experimentally validated in this study. Our secondary structure prediction indicates a six-stranded $\beta$ sheet configuration with an $\alpha$ helix located between the third and fourth $\beta$ strands, typical of OB-folds. The coiled regions, which could potentially represent the connecting loops, are known to augment the canonical ligand binding interface of OB-folds. It is interesting to note that the C-terminal end, which houses most of these loops, is independently capable of mediating high-affinity binding with gRNA in vitro; hence, this region most likely forms a significant part of the ligand binding interface of the KREPA4 OB-fold. KREPA4 was also predicted to contain an S1 RNA-binding motif within its midregion (amino acids 75-148) as a part of the OB-fold. Our binding data show that this region of the protein has the least contribution in binding function, which possibly suggests that the S1 motif known for its RNA-binding properties is not present in KREPA4. This observation is consistent with the reportedly weak similarity match to the $S 1$ motif obtained by motif scanning of T. brucei KREPA4 in a previous study (Salavati et al. 2006).

Editing accessory factors RBP16 and the MRP complex have been shown to facilitate the annealing of a few mRNA/ gRNAs (Schumacher et al. 2006; Ammerman et al. 2008). The MRP1/MRP2 complex plays a role in matchmaking the gRNAs with the cognate pre-mRNAs by unfolding the gRNA stem-loop structure facilitating the anchor duplex formation (Muller et al. 2001; Schumacher et al. 2006; Zikova et al. 2008). RBP16 acts as an RNA chaperone, destabilizing RNA secondary structure and its CSD, which belongs to the OBfold superfamily and contributes to its RNA annealing and unwinding activities (Ammerman et al. 2008). However, in vitro full-round and precleaved editing assays are conducted with purified editosomes in the absence of these or other proteins (Seiwert and Stuart 1994; Cruz-Reyes and SollnerWebb 1996; Igo et al. 2000; Kang et al. 2005; Reifur and Koslowsky 2008). This potentially implicates the presence of factors/proteins with RNA annealing function within the 20S editosome. KREPA4 is the first reported core component of the editing complex with annealing activity. It stimulates duplex formation between editing associated gRNA/premRNA pairs. The high-affinity gRNA-binding and RNA annealing activities of the KREPA4 seem to be mutually reliant on each other as interaction with the gRNA oligo(U) tail (or a U-rich region at the $3^{\prime}$ end) is a major requirement for both activities. Considering that there is no stable direct interaction of KREPA4 with the A6U5 pre-mRNA under the specific reaction conditions, it appears that the protein enters 
the annealing reaction as a gRNA-KREPA4 complex, which entails a high-affinity interaction with the gRNA oligo(U) tail. Also, KREPA4 does not stimulate annealing of complementary nonediting RNA pairs to any significant extent, which implies that the KREPA4-mediated annealing is specific to RNA editing substrates.

The annealing function of KREPA4 resides within the predicted OB-fold, which most likely does not interact with the gRNA stem-loop elements. Hence, it seems that the RNA annealing activity of KREPA4 is mostly independent of the recognition of stem-loop secondary structure elements by the LCRs and relies more upon the OB-fold-mediated, highaffinity interaction with the gRNA oligo(U) tail. When the predicted $\mathrm{OB}$-fold is disrupted into $\mathrm{S} 1$ and the $\mathrm{C}$ terminus, it is the $\mathrm{C}$ terminus with a strong binding affinity that demonstrates annealing activity, while the $S 1$ motif with the weakest binding is incapable of annealing as well (data not shown). Examples of OB-fold proteins with annealing function are well documented. DNA repair protein RecO from bacteria Deinococcus radiodurans has an N-terminal OB-fold domain that facilitates annealing of complementary singe-stranded DNA to form duplex DNA (Makharashvili et al. 2004). Another example is translation initiation factor eIF1A, which possesses RNA annealing activity in its OB-fold (Kwon et al. 2007). The mechanism by which KREPA4 facilitates RNA annealing is yet to be defined.

\section{MATERIALS AND METHODS}

\section{Construction of plasmids}

pRSETc expression vector (Invitrogen) was used to construct the N-terminal $6 \times$ His-tagged full-length KREPA4 and its truncated forms. BamHI-EcoRI DNA fragments were generated by PCR using full-length KREPA4 as a template and inserted into BamHIEcoRI digested pRSETc. The primer pairs used to generate the DNA fragments have been summarized in Table 1.

\section{Purification of recombinant KREPA4 proteins}

pRSETc expression vectors were transformed into $E$. coli strain BL21 (Rosetta DE3 pLysS; Novagen), which was then grown to a density of $0.6 \mathrm{OD}$ and induced with $1 \mathrm{mM}$ IPTG for either $3 \mathrm{~h}$ at $37^{\circ} \mathrm{C}$ or for $8 \mathrm{~h}$ at $18^{\circ} \mathrm{C}$. Cells were collected by centrifugation at $8000 \mathrm{rpm}$ for $10 \mathrm{~min}$ at $4^{\circ} \mathrm{C}$. A cell pellet from $1 \mathrm{~L}$ of induced culture was resuspended in $20 \mathrm{~mL}$ of lysis buffer $(50 \mathrm{mM}$ Tris-Cl at $\mathrm{pH}$ 8.0, $300 \mathrm{mM} \mathrm{NaCl}, 10 \mathrm{mM}$ imidazole, $0.1 \%$ Triton $\mathrm{X}$ and $1 \times$ Protease inhibitors). Lysozyme (Sigma) and DNase (protease free; Roche) were added to final concentrations of $1 \mathrm{mg} / \mathrm{mL}$ and $20 \mu \mathrm{g} / \mathrm{mL}$, respectively. After addition of $10 \mathrm{mM} \mathrm{MgCl}_{2}$, the cell lysate was incubated at $4^{\circ} \mathrm{C}$ for $30 \mathrm{~min}$ followed by centrifugation at $1000 \mathrm{~g}$ for $10 \mathrm{~min}$ at $4^{\circ} \mathrm{C}$. The supernatant from soft spin was further clarified by centrifugation at $16,000 \mathrm{~g}$ for $15 \mathrm{~min}$ at $4^{\circ} \mathrm{C}$. The cleared lysate was then incubated with $2 \mathrm{~mL}$ of IMAC Nickel charged resin (Bio-Rad) and rotated for $1 \mathrm{~h}$ at $4^{\circ} \mathrm{C}$. The resin was pre-equilibrated with binding buffer $\left(50 \mathrm{mM} \mathrm{NaH}_{2} \mathrm{PO}_{4}\right.$ at $\mathrm{pH} 8.0$, $500 \mathrm{mM} \mathrm{NaCl}$, and $10 \mathrm{mM}$ Imidazole). The resin-lysate slurry was loaded into a disposable $20 \mathrm{~mL}$ column, drained by gravity flow, and washed with $3 \times 10 \mathrm{~mL}$ wash buffer $\left(50 \mathrm{mM} \mathrm{NaH}_{2} \mathrm{PO}_{4}\right.$ at $\mathrm{pH}$ 8.0, $500 \mathrm{mM} \mathrm{NaCl}$, and $20 \mathrm{mM}$ Imidazole). The His-tagged recombinant proteins were eluted with $10 \mathrm{~mL}$ of elution buffer ( $50 \mathrm{mM} \mathrm{NaH}_{2} \mathrm{PO}_{4}$ at $\mathrm{pH} 8.0,500 \mathrm{mM} \mathrm{NaCl}, 500 \mathrm{mM}$ Imidazole, and $10 \%$ glycerol), concentrated to a volume of $2.5 \mathrm{~mL}$ using an Amicon centrifugal filter device (Millipore) of appropriate size, and immediately subjected to dialysis in three changes of Tris buffer $(20 \mathrm{mM}$ Tris- $\mathrm{HCl}$ at $\mathrm{pH} 7.6,50 \mathrm{mM} \mathrm{KCl}$ and $5 \mathrm{mM}$ $\mathrm{MgCl}_{2}$ ). Glycerol was added to a final concentration of $30 \%$ and samples were stored at $-80^{\circ} \mathrm{C}$. The concentration of proteins was determined by means of their His-tag in a quantitative Western blot using Versadoc (Bio-Rad).

\section{In vitro transcription and labeling of RNA}

A DNA template for transcription of gA6[14] gRNA was made by PCR amplification of the plasmid-encoded gA6[14] gene. PCRpurified DNA $(2 \mu \mathrm{g})$ was transcribed in a $40 \mu \mathrm{L}$ reaction with 3 $\mu \mathrm{L}$ of T7 RNA polymerase (18 units/ $\mu \mathrm{L}$; Promega), $1 \times$ transcription buffer (Promega), $10 \mathrm{mM}$ DTT, $0.75 \mathrm{mM}$ each of rATP, rCTP, and rGTP, $7.5 \mu \mathrm{M}$ of rUTP, 40 units of RNasin (Promega), and $100 \mu \mathrm{Ci}$ of $800 \mathrm{Ci} / \mathrm{mmol}\left[\alpha-{ }^{32} \mathrm{P}\right] \mathrm{UTP}$. The reaction was incubated at $37^{\circ} \mathrm{C}$ for $3 \mathrm{~h}$ followed by digestion with 2 units of RNase free DNase (Promega) for $30 \mathrm{~min}$ at $37^{\circ} \mathrm{C}$. RNA was purified on a $9 \%$ polyacrylamide-7M urea gel and eluted from the gel slice in NaOAc elution buffer (0.3 M NaOAc at pH 5.2, $0.1 \%$ SDS, and $1 \mathrm{mM}$ EDTA) by rotation overnight. The radiolabeled RNA was concentrated by ethanol precipitation and finally the RNA pellet was resuspended in DEPC water. Gel-purified RNA was quantified by scintillation counting, by taking counts before and after gel purification.

For annealing and EMSA competition assays, the unlabeled gA6 [14] gRNA and gA6[14] gRNA lacking an oligo(U) tail were prepared by T7 polymerase (Promega) transcription of PCRgenerated templates as previously described (Seiwert et al. 1996). For the EMSA competition assays, the unlabeled competitor RNAs were transcribed in vitro by T7 polymerase (Promega) transcription of synthetic DNA oligonucleotides listed in Table 1, in combination with a T7 promoter oligonucleotide that is complementary to the underlined part of the sequences. The 90-nt pBlueScript SK+ (Stratagene) RNA was generated by in vitro transcription of the NotI linearized plasmid. All RNAs were purified on urea-containing (7M) polyacrylamide gels.

For the RNA annealing assay, the two synthetic complementary RNAs were transcribed in vitro by T7 polymerase (Promega) transcription of synthetic DNA oligonucleotides listed in Table 1, in combination with a T7 promoter oligonucleotide that is complementary to the underlined part of the sequences. A6U5 premRNA was prepared by T7 polymerase (Promega) transcription of the PCR-generated template as previously described (Seiwert et al. 1996). CYb pre-mRNA (104 nt) was synthesized in vitro by T7 polymerase transcription of BamHI linealized DNA template as previously described (Salavati et al. 2002). Natural CYb gRNA was prepared by T7 RNA polymerase from two complementary oligonucleotides as previously described (Salavati et al. 2002). 37-mer CYb gRNA was synthesized by T7 RNA polymerase from two complementary oligonucleotides as previously described (Salavati et al. 2002). All RNAs were purified on urea containing (7M) polyacrylamide gels. A6U5 pre-mRNA, CYb pre-mRNA, and synthetic 


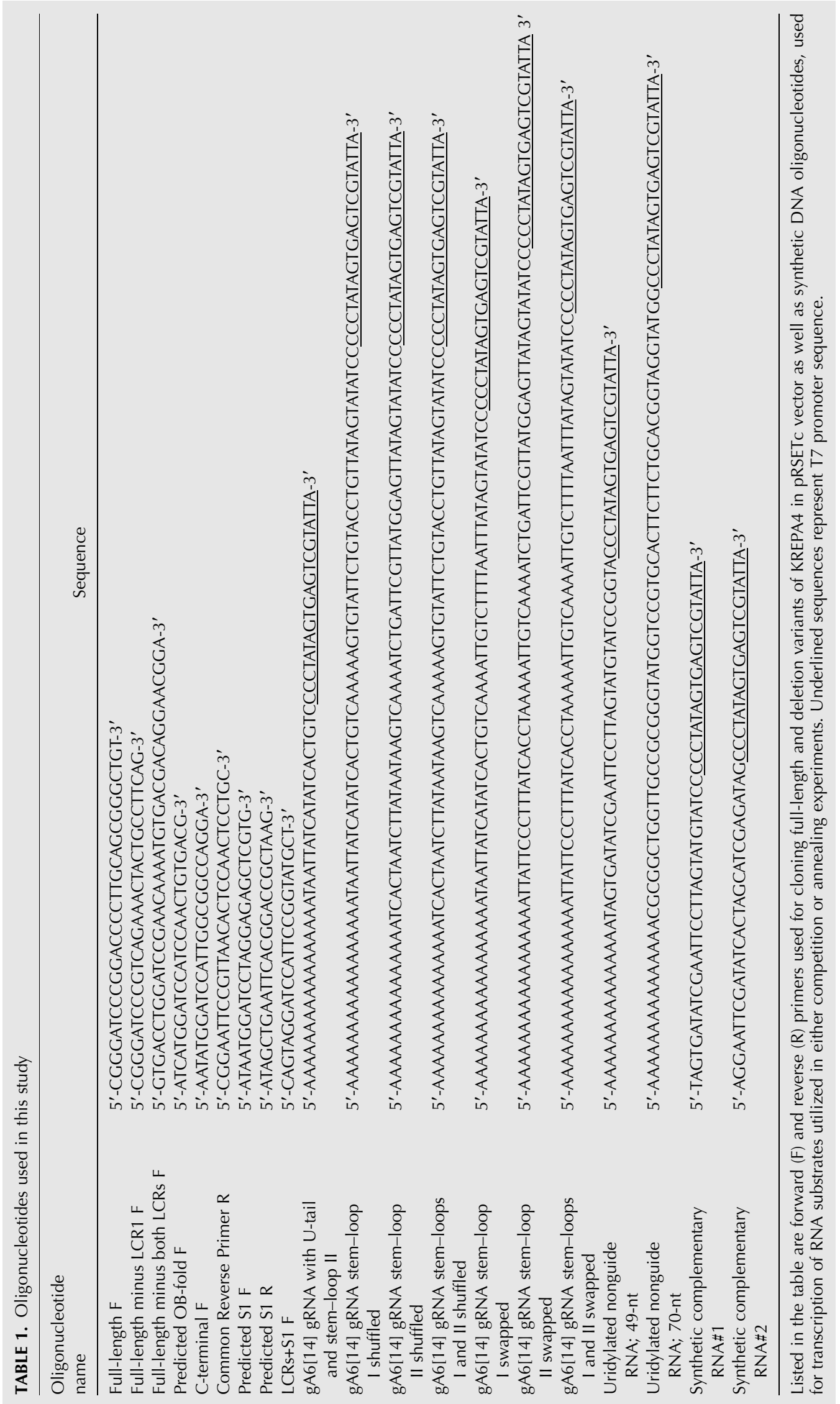


complementary RNA \#1 were $5^{\prime}{ }^{32} \mathrm{P}$ labeled using T4 polynucleotide kinase and $\left[\gamma^{-}{ }^{32} \mathrm{P}\right]$ ATP.

\section{Gel shift assays}

In order to establish the protein concentration in the optimal range for final $K_{\mathrm{d}}$ determination, an initial estimation of the apparent equilibrium dissociation constant $\left(K_{\mathrm{d}}\right.$ app) was carried out. Gel shift assays were performed by incubating increasing concentrations (0.1$9600 \mathrm{nM}$ ) of purified KREPA4 (full-length and deletion variants) with $0.1 \mathrm{nM}(\sim 30,000 \mathrm{CPM})$ of internally $\left[\alpha-{ }^{32} \mathrm{P}\right]$ UTP labeled gA6 [14] gRNA substrate (heated at $95^{\circ} \mathrm{C}$ for $5 \mathrm{~min}$ ) in buffer RBB50 (20 mM Tris- $\mathrm{HCl}$ at $\mathrm{pH} 7.6,50 \mathrm{mM} \mathrm{KCl}, 5 \mathrm{mM} \mathrm{MgCl}, 100 \mu \mathrm{g} / \mathrm{mL}$ BSA, $10 \%$ glycerol, and $1 \mathrm{mM} \mathrm{DTT),} 100 \mathrm{mM} \mathrm{KCl}$, and 20 units RNasin (Promega) in a $20 \mu \mathrm{L}$ volume for $30 \mathrm{~min}$ at room temperature. Samples were mixed with gel loading dye $(0.25 \%$ bromophenol blue, $0.25 \%$ xylene cyanol, and $30 \%$ glycerol) and then loaded onto native $10 \%$ TBE gels (Bio-Rad) that were pre-run at 110 $\mathrm{V}$ for $15 \mathrm{~min}$ in $0.5 \times \mathrm{TBE}$ at $4^{\circ} \mathrm{C}$. The gels were run under the same conditions for $2 \mathrm{~h}$, fixed in $10 \%$ isopropanol plus $7 \%$ acetic acid for $30 \mathrm{~min}$ and dried for $30 \mathrm{~min}$ on a gel dryer and visualized by a PhosphorImager (Bio-Rad). Bound and unbound RNA were quantified using the Quantity One software (Bio-Rad). The sum of the bound complexes in each lane was considered as the total bound fraction. The apparent equilibrium dissociation constant (overall $K_{\mathrm{d}}$ app), i.e., the KREPA4 protein concentration at which $50 \%$ of the RNA was bound, was determined by fits to the Hill equation using Graph Pad Prism software (GraphPad Software, Inc.).

To estimate the active protein concentration and the actual value of equilibrium dissociation constant, $K_{\mathrm{d}}$, increasing concentrations $(0.1-1.2 \mathrm{nM})$ of the internally $\left[\alpha-{ }^{32} \mathrm{P}\right]$ UTP labeled gA6[14] gRNA substrate were incubated with a constant amount of KREPA4 (full-length and deletion variants). This invariant protein concentration corresponded to about two times the $K_{\mathrm{d}}$ app as determined above. This lead to the percentage of RNA bound varying from $\sim 30 \%$ to $65 \%$ over the range of the titration. Binding reactions were carried out under the same conditions as mentioned above. The data were analyzed by nonlinear curve fitting methods using Graph Pad Prism software (GraphPad Software, Inc.), and values of equilibrium dissociation constant, $K_{\mathrm{d}}$, and active protein concentration, $\mathrm{B}_{\max }$, were determined as best fits to the experimental data.

Competition experiments were carried out as described above using a fixed amount of protein that resulted in $\sim 30 \%-40 \%$ bound RNA. A saturating concentration of the radiolabeled gA6[14] gRNA (that resulted in all protein molecules being bound by the radiolabeled RNA) was mixed with 1-, 10-, 100-, or 1000fold molar excess of unlabeled competitor RNA in buffer prior to the addition of each protein. The percent competition was estimated as the ratio of bound RNA in the presence of an unlabeled competitor over bound RNA without the competitor.

Supershift assays were performed in the same way as described above using anti KREPA4 polyclonal antibodies that we had raised against two different regions of the protein. One microliter of the undiluted antibody was used for each KREPA4 truncation.

\section{RNA annealing assay}

Annealing reactions were performed as described previously (Muller et al. 2001). Equimolar concentrations (10 nM) of gA6[14] gRNA (with or without the U-tail) and 5' end labeled
A6U5 pre-mRNA were used in the absence and presence of indicated amounts of KREPA4 (full-length or predicted OB-fold). CYb pre-mRNA $(10 \mathrm{nM})$ and 37-mer CYb gRNA $(20 \mathrm{nM})$ were used at a 1:2 ratio and so were the two synthetic complementary RNAs. The reactions were performed in $20 \mu \mathrm{L}$ of buffer containing $6 \mathrm{mM}$ HEPES-KOH at $\mathrm{pH} 7.5,50 \mathrm{mM} \mathrm{KCl}, 2.1 \mathrm{mM} \mathrm{MgCl}_{2}$, $0.1 \mathrm{mM} \mathrm{Na}_{2}$ EDTA, $0.5 \mathrm{mM}$ DTT, $750 \mathrm{nM}$ BSA, and $2 \%$ glycerol. RNA substrates were individually incubated at $70^{\circ} \mathrm{C}$ for $2 \mathrm{~min}$ and cooled to room temperature for $15 \mathrm{~min}$. Reaction components were mixed together and incubated for $20 \mathrm{~min}$ at $28^{\circ} \mathrm{C}$. The reactions were stopped by the addition of $20 \mu \mathrm{g}$ of proteinase $\mathrm{K}$, $0.5 \%$ SDS, and $2.5 \mathrm{mM} \mathrm{Na}_{2}$ EDTA, and further incubated for 15 min at $28^{\circ} \mathrm{C}$. Samples were mixed with $2 \mu \mathrm{L}$ of $6 \times$ gel loading dye and loaded onto native $10 \%$ TBE gels (Bio-Rad) that were pre-run at $110 \mathrm{~V}$ for $15 \mathrm{~min}$ in $0.5 \times \mathrm{TBE}$ buffer and run at $110 \mathrm{~V}$ for $1 \mathrm{~h}$ at $4^{\circ} \mathrm{C}$. The gels were run under the same conditions for $2 \mathrm{~h}$, fixed in $10 \%$ isopropanol plus $7 \%$ acetic acid for $30 \mathrm{~min}$, dried, and analyzed using the Bio-Rad Quantity One PhosphorImager. The percent of the annealed products was estimated as the ratio of the pre-mRNA hybridized to the gRNA in the presence of protein over the pre-mRNA/gRNA self-hybridization in the absence of protein.

\section{KREPA4 secondary structure prediction}

The secondary structure of KREPA4 was predicted using Porter, available as a public web server at http://distill.ucd.ie/porter/ (Pollastri and McLysaght 2005).

\section{ACKNOWLEDGMENTS}

We thank Hamed Shateri Najafabadi for critical reviewing of the manuscript and Houtan Moshiri for radiolabeling of annealing substrates. This research is supported by National Sciences and Engineering Research Council of Canada (NSERC) grant no. 328186 to R.S. S.K. was supported by a Robert P. Harpur Fellowship in Parasitology.

Received February 11, 2010; accepted July 19, 2010.

\section{REFERENCES}

Acestor N, Panigrahi AK, Carnes J, Zikova A, Stuart KD. 2009. The MRB1 complex functions in kinetoplastid RNA processing. RNA 15: 277-286.

Ammerman ML, Fisk JC, Read LK. 2008. gRNA/pre-mRNA annealing and RNA chaperone activities of RBP16. RNA 14: 1069-1080.

Aphasizhev R, Sbicego S, Peris M, Jang SH, Aphasizheva I, Simpson AM, Rivlin A, Simpson L. 2002. Trypanosome mitochondrial 3' terminal uridylyl transferase (TUTase): The key enzyme in U-insertion/deletion RNA editing. Cell 108: 637-648.

Blom D, Burg J, Breek CK, Speijer D, Muijsers AO, Benne R. 2001. Cloning and characterization of two guide RNA-binding proteins from mitochondria of Crithidia fasciculata: gBP27, a novel protein, and gBP29, the orthologue of Trypanosoma brucei gBP21. Nucleic Acids Res 29: 2950-2962.

Blum B, Bakalara N, Simpson L. 1990. A model for RNA editing in kinetoplastid mitochondria: 'Guide' RNA molecules transcribed from maxicircle DNA provide the edited information. Cell 60: 189-198.

Bochkarev A, Bochkareva E. 2004. From RPA to BRCA2: Lessons from single-stranded DNA binding by the OB-fold. Curr Opin Struct Biol 14: 36-42. 
Brecht M, Niemann M, Schluter E, Muller UF, Stuart K, Goringer HU. 2005. TbMP42, a protein component of the RNA editing complex in African trypanosomes, has endo-exoribonuclease activity. Mol Cell 17: 621-630.

Bycroft M, Hubbard TJ, Proctor M, Freund SM, Murzin AG. 1997. The solution structure of the S1 RNA binding domain: A member of an ancient nucleic acid-binding fold. Cell 88: 235-242.

Cruz-Reyes J, Sollner-Webb B. 1996. Trypanosome U-deletional RNA editing involves guide RNA-directed endonuclease cleavage, terminal U exonuclease, and RNA ligase activities. Proc Natl Acad Sci 93: 8901-8906.

Drozdz M, Palazzo SS, Salavati R, O’Rear J, Clayton C, Stuart K. 2002. TbMP81 is required for RNA editing in Trypanosoma brucei. EMBO J 21: 1791-1799.

Fisk JC, Presnyak V, Ammerman ML, Read LK. 2009. Distinct and overlapping functions of MRP1/2 and RBP16 in mitochondrial RNA metabolism. Mol Cell Biol 29: 5214-5225.

Golas MM, Bohm C, Sander B, Effenberger K, Brecht M, Stark H, Goringer HU. 2009. Snapshots of the RNA editing machine in trypanosomes captured at different assembly stages in vivo. $E M B O$ J 28: 766-778.

Guo X, Ernst NL, Stuart KD. 2008. The KREPA3 zinc finger motifs and OB-fold domain are essential for RNA editing and survival of Trypanosoma brucei. Mol Cell Biol 28: 6939-6953.

Hashimi H, Zikova A, Panigrahi AK, Stuart KD, Lukes J. 2008. TbRGG1, an essential protein involved in kinetoplastid RNA metabolism that is associated with a novel multiprotein complex. RNA 14: 970-980.

Hayman ML, Read LK. 1999. Trypanosoma brucei RBP16 is a mitochondrial Y-box family protein with guide RNA binding activity. J Biol Chem 274: 12067-12074.

Hermann T, Schmid B, Heumann H, Goringer HU. 1997. A threedimensional working model for a guide RNA from Trypanosoma brucei. Nucleic Acids Res 25: 2311-2318.

Huang CE, O'Hearn SF, Sollner-Webb B. 2002. Assembly and function of the RNA editing complex in Trypanosoma brucei requires band III protein. Mol Cell Biol 22: 3194-3203.

Igo RP Jr, Palazzo SS, Burgess ML, Panigrahi AK, Stuart K. 2000. Uridylate addition and RNA ligation contribute to the specificity of kinetoplastid insertion RNA editing. Mol Cell Biol 20: 84478457.

Igo RP Jr, Lawson SD, Stuart K. 2002. RNA sequence and base pairing effects on insertion editing in Trypanosoma brucei. Mol Cell Biol 22: $1567-1576$

Kang X, Rogers K, Gao G, Falick AM, Zhou S, Simpson L. 2005. Reconstitution of uridine-deletion precleaved RNA editing with two recombinant enzymes. Proc Natl Acad Sci 102: 1017-1022.

Koller J, Muller UF, Schmid B, Missel A, Kruft V, Stuart K, Goringer HU. 1997. Trypanosoma brucei gBP21. An arginine-rich mitochondrial protein that binds to guide RNA with high affinity. J Biol Chem 272: 3749-3757.

Koslowsky DJ, Riley GR, Feagin JE, Stuart K. 1992. Guide RNAs for transcripts with developmentally regulated RNA editing are present in both life cycle stages of Trypanosoma brucei. Mol Cell Biol 12: 2043-2049.

Koslowsky DJ, Reifur L, Yu LE, Chen W. 2004. Evidence for U-tail stabilization of gRNA/mRNA interactions in kinetoplastid RNA editing. RNA Biol 1: 28-34.

Kwon SH, Lee IH, Kim NY, Choi DH, Oh YM, Bae SH. 2007. Translation initiation factor eIF1A possesses RNA annealing activity in its oligonucleotide-binding fold. Biochem Biophys Res Commun 361: 681-686.

Lin JJ, Zakian VA. 1996. The Saccharomyces CDC13 protein is a single-strand TG1-3 telomeric DNA-binding protein in vitro that affects telomere behavior in vivo. Proc Natl Acad Sci 93: 13760-13765.

Lukes J, Hashimi H, Zikova A. 2005. Unexplained complexity of the mitochondrial genome and transcriptome in kinetoplastid flagellates. Curr Genet 48: 277-299.
Madison-Antenucci S, Sabatini RS, Pollard VW, Hajduk SL. 1998. Kinetoplastid RNA-editing-associated protein 1 (REAP-1): A novel editing complex protein with repetitive domains. EMBO J 17: 6368-6376.

Madison-Antenucci S, Grams J, Hajduk SL. 2002. Editing machines: The complexities of trypanosome RNA editing. Cell 108: 435438 .

Makharashvili N, Koroleva O, Bera S, Grandgenett DP, Korolev S. 2004. A novel structure of DNA repair protein $\mathrm{RecO}$ from Deinococcus radiodurans. Structure 12: 1881-1889.

Matthews JM, Sunde M. 2002. Zinc fingers-folds for many occasions. IUBMB Life 54: 351-355.

Miller MM, Halbig K, Cruz-Reyes J, Read LK. 2006. RBP16 stimulates trypanosome RNA editing in vitro at an early step in the editing reaction. RNA 12: 1292-1303.

Muller UF, Lambert L, Goringer HU. 2001. Annealing of RNA editing substrates facilitated by guide RNA-binding protein gBP21. EMBO J 20: 1394-1404.

Nugent CI, Hughes TR, Lue NF, Lundblad V. 1996. Cdc13p: A singlestrand telomeric DNA-binding protein with a dual role in yeast telomere maintenance. Science 274: 249-252.

O'Hearn SF, Huang CE, Hemann M, Zhelonkina A, Sollner-Webb B. 2003. Trypanosoma brucei RNA editing complex: Band II is structurally critical and maintains band V ligase, which is nonessential. Mol Cell Biol 23: 7909-7919.

Panigrahi AK, Schnaufer A, Carmean N, Igo RP Jr, Gygi SP, Ernst NL, Palazzo SS, Weston DS, Aebersold R, Salavati R, et al. 2001. Four related proteins of the Trypanosoma brucei RNA editing complex. Mol Cell Biol 21: 6833-6840.

Panigrahi AK, Zikova A, Dalley RA, Acestor N, Ogata Y, Anupama A, Myler PJ, Stuart KD. 2008. Mitochondrial complexes in Trypanosoma brucei: A novel complex and a unique oxidoreductase complex. Mol Cell Proteomics 7: 534-545.

Pelletier M, Miller MM, Read LK. 2000. RNA-binding properties of the mitochondrial Y-box protein RBP16. Nucleic Acids Res 28: 1266-1275.

Piller KJ, Rusche LN, Cruz-Reyes J, Sollner-Webb B. 1997. Resolution of the RNA editing gRNA-directed endonuclease from two other endonucleases of Trypanosoma brucei mitochondria. RNA 3: 279290.

Pollastri G, McLysaght A. 2005. Porter: A new, accurate server for protein secondary structure prediction. Bioinformatics 21: 17191720.

Reifur L, Koslowsky DJ. 2008. Trypanosoma brucei ATPase subunit 6 mRNA bound to gA6-14 forms a conserved three-helical structure. RNA 14: 2195-2211.

Riley GR, Corell RA, Stuart K. 1994. Multiple guide RNAs for identical editing of Trypanosoma brucei apocytochrome b mRNA have an unusual minicircle location and are developmentally regulated. J Biol Chem 269: 6101-6108.

Salavati R, Panigrahi AK, Morach BA, Palazzo SS, Igo RP, Stuart K. 2002. Endoribonuclease activities of Trypanosoma brucei mitochondria. Mol Biochem Parasitol 120: 23-31.

Salavati R, Ernst NL, O’Rear J, Gilliam T, Tarun S Jr, Stuart K. 2006. KREPA4, an RNA binding protein essential for editosome integrity and survival of Trypanosoma brucei. RNA 12: 819-831.

Schmid B, Riley GR, Stuart K, Goringer HU. 1995. The secondary structure of guide RNA molecules from Trypanosoma brucei. Nucleic Acids Res 23: 3093-3102.

Schnaufer A, Ernst NL, Palazzo SS, O’Rear J, Salavati R, Stuart K. 2003. Separate insertion and deletion subcomplexes of the Trypanosoma brucei RNA editing complex. Mol Cell 12: 307-319.

Schnaufer A, Wu M, Park YJ, Nakai T, Deng J, Proff R, Hol WG, Stuart KD. 2010. A protein-protein interaction map of trypanosome $\sim 20$ S editosomes. J Biol Chem 285: 5282-5295.

Schumacher MA, Karamooz E, Zikova A, Trantirek L, Lukes J. 2006. Crystal structures of T. brucei MRP1/MRP2 guide-RNA binding complex reveal RNA matchmaking mechanism. Cell 126: 701711. 
Seiwert SD, Stuart K. 1994. RNA editing: Transfer of genetic information from gRNA to precursor mRNA in vitro. Science 266: 114-117.

Seiwert SD, Heidmann S, Stuart K. 1996. Direct visualization of uridylate deletion in vitro suggests a mechanism for kinetoplastid RNA editing. Cell 84: 831-841.

Setzer DR, Menezes SR, Del RS, Hung VS, Subramanyan G. 1996. Functional interactions between the zinc fingers of Xenopus transcription factor IIIA during 5S rRNA binding. RNA 2: 1254-1269.

Simpson L, Aphasizhev R, Gao G, Kang X. 2004. Mitochondrial proteins and complexes in Leishmania and Trypanosoma involved in U-insertion/deletion RNA editing. RNA 10: 159-170.

Simpson L, Aphasizhev R, Lukes J, Cruz-Reyes J. 2010. Guide to the nomenclature of kinetoplastid RNA editing: A proposal. Protist 161: 2-6.

Stuart KD, Schnaufer A, Ernst NL, Panigrahi AK. 2005. Complex management: RNA editing in trypanosomes. Trends Biochem Sci 30: $97-105$.
Theobald DL, Mitton-Fry RM, Wuttke DS. 2003. Nucleic acid recognition by OB-fold proteins. Annu Rev Biophys Biomol Struct 32: 115-133.

Vanhamme L, Perez-Morga D, Marchal C, Speijer D, Lambert L, Geuskens M, Alexandre S, Ismaili N, Goringer U, Benne R, et al. 1998. Trypanosoma brucei TBRGG1, a mitochondrial oligo(U)binding protein that co-localizes with an in vitro RNA editing activity. J Biol Chem 273: 21825-21833.

Wootton JC, Federhen S. 1996. Analysis of compositionally biased regions in sequence databases. Methods Enzymol 266: 554-571.

Worthey EA, Schnaufer A, Mian IS, Stuart K, Salavati R. 2003. Comparative analysis of editosome proteins in trypanosomatids. Nucleic Acids Res 31: 6392-6408.

Zikova A, Kopecna J, Schumacher MA, Stuart K, Trantirek L, Lukes J. 2008. Structure and function of the native and recombinant mitochondrial MRP1/MRP2 complex from Trypanosoma brucei. Int J Parasitol 38: 901-912. 

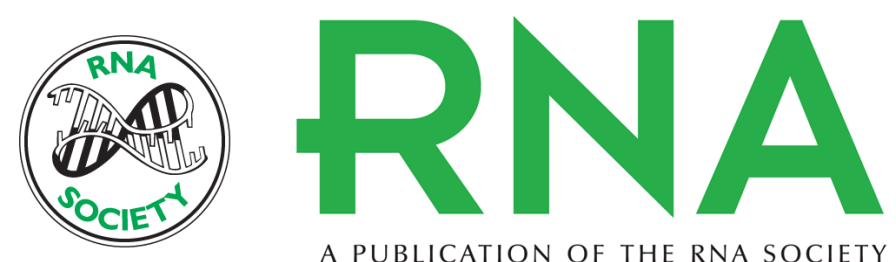

A PUBLICATION OF THE RNA SOCIETY

\section{OB-fold domain of KREPA4 mediates high-affinity interaction with guide RNA and possesses annealing activity}

Smriti Kala and Reza Salavati

RNA 2010 16: 1951-1967 originally published online August 16, 2010

Access the most recent version at doi:10.1261/rna.2124610

\begin{aligned} & References $\begin{array}{l}\text { This article cites } 58 \text { articles, } 31 \text { of which can be accessed free at: } \\ \text { http://rnajournal.cshlp.org/content/16/10/1951.full.html\#ref-list-1 }\end{array} \\ &$ Open Access Freely available online through the RNA Open Access option. \\ & Email Alerting Freely available online through the RNA Open Access option. \\ & Service $\begin{array}{l}\text { Receive free email alerts when new articles cite this article - sign up in the box at the } \\ \text { top right corner of the article or click here. }\end{array} \\ &$\hline\end{aligned}

To subscribe to $R N A$ go to:

http://rnajournal.cshlp.org/subscriptions 